\title{
Review Article \\ Complementary and Alternative Therapies for Autism Spectrum Disorder
}

\author{
Natascia Brondino, Laura Fusar-Poli, Matteo Rocchetti, Umberto Provenzani, \\ Francesco Barale, and Pierluigi Politi \\ Department of Brain and Behavioral Sciences, Section of Psychiatry, University of Pavia, Via Bassi 21, 27100 Pavia, Italy \\ Correspondence should be addressed to Natascia Brondino; natascia.brondino@libero.it
}

Received 13 January 2015; Revised 23 March 2015; Accepted 30 March 2015

Academic Editor: Karen J. Sherman

Copyright (c) 2015 Natascia Brondino et al. This is an open access article distributed under the Creative Commons Attribution License, which permits unrestricted use, distribution, and reproduction in any medium, provided the original work is properly cited.

Background. Complementary and alternative medicine (CAM) represents a popular therapeutic option for patients with autism spectrum disorder (ASD). Unfortunately, there is a paucity of data regarding the efficacy of CAM in ASD. The aim of the present systematic review is to investigate trials of CAM in ASD. Material and Methods. We searched the following databases: MEDLINE, EMBASE, Cochrane Database of Systematic Reviews, CINAHL, Psychology and Behavioral Sciences Collection, Agricola, and Food Science Source. Results. Our literature search identified 2687 clinical publications. After the title/abstract screening, 139 publications were obtained for detailed evaluation. After detailed evaluation 67 studies were included, from hand search of references we retrieved 13 additional studies for a total of 80 . Conclusion. There is no conclusive evidence supporting the efficacy of CAM therapies in ASD. Promising results are reported for music therapy, sensory integration therapy, acupuncture, and massage.

\section{Introduction}

Autism spectrum disorder (ASD) is a heterogeneous group of neurodevelopmental conditions characterized by the presence of impaired social communication and reciprocity and of restricted and stereotyped pattern of behaviors and interests. In the last few decades, the prevalence of ASD has increased dramatically, configuring a sort of "epidemics" [1]. Usually, it affects boys more than girls (4:1 ratio) and it is a lifelong condition, generally diagnosed in early childhood [2]. Despite the public concern about this phenomenon and the interest of the scientific community, there are still controversies about ASD etiology. It is hypothesized that ASD is caused by a combination of genetic and environmental stimuli, but no clear pathogenesis has been defined [3]. Effective therapies for ASD core symptoms have not yet been developed. Evidence-based first-line treatments are represented by behavioral therapies (such as TEACCH or ABA) [4]. Use of pharmacological medications (such as risperidone or aripiprazole) $[5,6]$ is usually limited to treating behavioral symptoms of the disorder like irritability or aggressiveness. Unfortunately, despite the dramatic effect sizes for these problem behaviors, the pharmacological approach to core symptoms has led to inconclusive results and is sometimes burdened by severe adverse events [7]. Families of children with autism are usually worried by potential drug side effects and are continuously looking for treatments which are more secure. As a consequence, in recent years, there has been an increasing interest for complementary and alternative medicine, not only in ASD, but also in several pathological conditions.

According to the definition of the Cochrane Collaboration, "complementary and alternative medicine (CAM) is a broad domain of healing resources that encompasses all health systems, modalities, and practices and their accompanying theories and beliefs, other than those intrinsic to the politically dominant health system of a particular society or culture in a given historical period. CAM includes all such practices and ideas self-defined by their users as preventing or treating illness or promoting health and well-being. Boundaries within CAM and between the CAM domain and that of the dominant system are not always sharp or fixed." CAMs have become very popular therapies among adults and children with ASD [8]. In 2006, according to an Internet 
survey involving a sample of 540 families from the Autism Society of America and the autism organizations worldwide, each family with a child with ASD has tried a mean of 7 treatments [9], among which many were CAMs. Particularly, it has recently been estimated that $28 \%$ of children with ASD are treated with CAM [8]: CAM usage appears to be more common among Caucasian families with high economic income. It is of note that even before the diagnosis, nearly one-third of children have already received a CAM treatment and $9 \%$ of this population has used a potentially harmful therapy such as chelation [10]. Previously, higher CAM usage among families with an ASD child had been reported (ranging from 52 to $74 \%$ ) [11, 12]. Compared to the work of Perrin et al., previous studies considered a wider range of CAMs and enrolled older subjects as participants, which could explain the resulting higher figures. Type of CAM use appears to be stable over time: biological therapies, in particular elimination or special diets, are the most frequent [8-12].

Despite its popularity, the use of CAMs in ASD is controversial; recently more methodologically sounded trials have been designed and conducted in order to test the efficacy of different CAM therapies, and the knowledge about CAMs is moving from an anecdotal form to a more scientific one. The aim of the present systematic review is to give a comprehensive overlook of the efficacy of CAM in ASD.

\section{Material and Methods}

In October 2014, we searched the following databases: MEDLINE, EMBASE, Cochrane Database of Systematic Reviews, CINAHL, Psychology and Behavioral Sciences Collection, Agricola, and Food Science Source. The search terms were as follows: 'asd'/exp OR asd OR 'autism'/exp OR autism AND ('spectrum'/exp OR spectrum) AND ('disorder'/exp OR disorder) OR autistic ${ }^{*}$ AND complementary OR alternative AND ('medicine'/exp OR medicine) OR herbal OR 'music'/exp OR music AND ('therapy'/exp OR therapy) OR 'dance'/exp OR dance AND ('therapy'/exp OR therapy) OR 'diet'/exp OR diet OR cam OR 'yoga'/exp OR yoga OR supplement OR plant OR botanical. The search strategy had no time restriction but was limited to articles in English. Additionally, all recovered papers were reviewed for further relevant references. Researchers in the field were reached to obtain additional or unpublished data, if available.

Two researchers (Natascia Brondino and Laura FusarPoli) independently reviewed all information about the articles provided by the databases. Any discrepancies were solved by consensus.

Our inclusion criteria were broad on study design, including both randomized and open label trials, yielding primary results on the effects of CAM administration in core symptoms of ASD. ASD was defined according to internationally valid diagnostic criteria such as the International Classification of Diseases (ICD) or the Diagnostic and Statistical Manual of Mental Disorders (DSM). We excluded case report and case series. We did not consider off-label drugs (such as oxytocin, secretin, and antibiotics) as CAM.
Additionally, we did not include trials on melatonin in ASD (for this purpose see the review written by Tordjman et al. [93] in 2013) as it is generally used to treat sleep problems in autistic patients and not intended to treat core symptoms of ASD.

\section{Results}

Our literature search identified 2687 clinical publications. After the title/abstract screening, 139 publications were obtained for detailed evaluation. After detailed evaluation 67 studies were included; from hand search of references we retrieved 13 additional studies for a total of 80 .

\section{Biologically Based Treatments}

Biological CAM treatments usually include dietary interventions, vitamin supplements, and herbal remedies [8]. There are several critical mechanisms that could be advocate to explain the biological effect of CAM: in particular, researchers in the field have pointed out how Natural Killer (NK) cell activation or immune system modulation may play a key role in several biological CAMs (i.e., elimination diets or probiotics) [94]. Additionally, other potential pathways involved in biologically based CAMs include antioxidant and anti-inflammatory activity (i.e., flavonoids and probiotics) [95], neuroprotection (i.e., omega 3) [96], or modulation of the neurotransmitter-induced response (i.e., L-carnosine) [97]. In addition, more discussed CAMs (Hyperbaric Oxygen Therapy (HBOT) or chelation) could be included in this section as the rationale for their use relies on a biological mechanism. In particular, chelation tries to eliminate toxic metals from blood [98] while HBOT aims at enhancing blood oxygen level in order to determine a positive impact on several neurological functions such as language, memory, and cognition [99].

4.1. Dietary Interventions. Among CAMs currently used in autism, elimination diets, especially gluten and/or caseinfree diets, are one of the most popular (Table 1). In fact, Levy and Hyman have reported that 1 in every 7 children is put on this nutritional regimen [100]. The rationale behind the use of a specific dietary regimen relies on the presence of specific food allergen (such as casein or gluten) which could enhance immune response in predisposed subjects or trigger autoimmunity $[101,102]$. Another theory is that gluten and casein may originate opiate-active metabolites in the gut that could reach the systemic circulation (the "opioid excess theory" of autism) [103]. Additionally, several gastrointestinal abnormalities have been observed in subjects with ASD, such as increased permeability of the gut barrier and bacterial overgrowth which could benefit from elimination diet [34, 104]. Elimination diets showed modest clinical effect in treating children with Attention-Deficit Hyperactivity Disorder (ADHD) [105], which shares some features with ASD [106].

Focusing on autism, the first studies investigating the efficacy of a gluten- and casein-free diet were conducted in the 1990s and were mostly uncontrolled trials (i.e., [107-109]). 


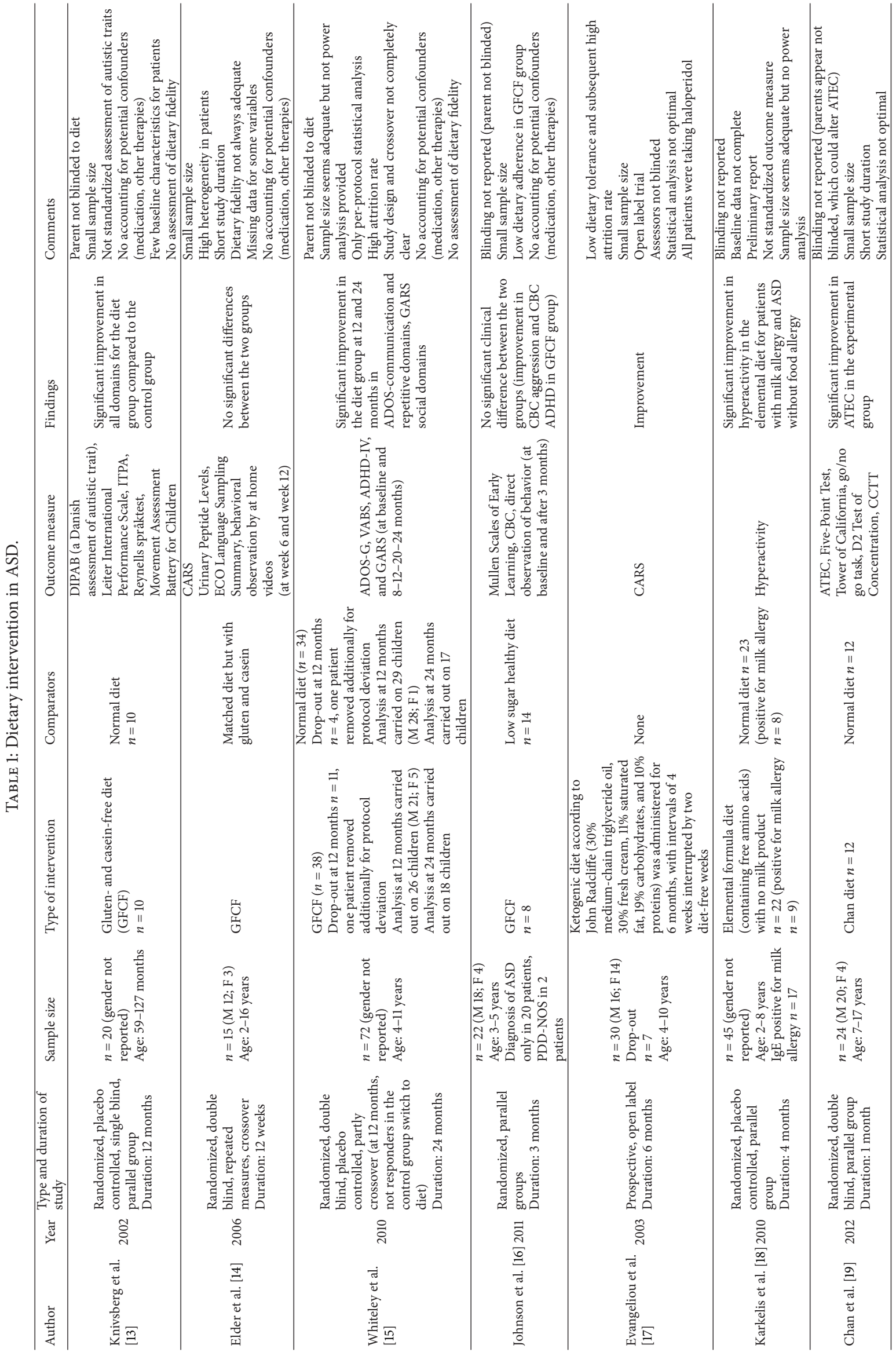




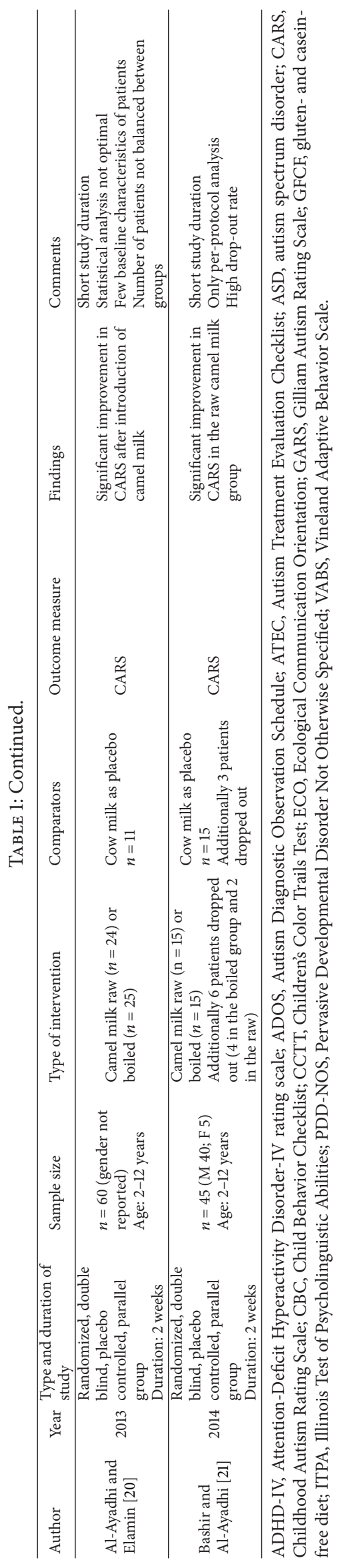


Although all these reports showed a significant improvement of ASD symptoms after the elimination diet, there were several methodological flaws, such as the lack of a control group, poor diagnostic characterization, small sample sizes, use of unstandardized outcome measures, and absence of control on dietary adhesion. The first randomized controlled trial was done in 2002 [13]: the authors enrolled 10 pairs of autistic children matched for age, cognitive level, and severity. In each pair, one child was randomly assigned to a gluten- and caseinfree (GFCF) diet while the other maintained the normal diet. The follow-up time was one year. It was a single blind study and the authors observed modification of attention, social and emotional factor, cognitive level, language, and motor skills in the elimination diet group. Unfortunately, the study is flawed by several caveats such as the inclusion of patients with "abnormal urinary peptide patterns," which could limit the generalizability of the findings, the single blind design, and the lack of dietary fidelity evaluation and of internationally valid outcome measures. Later on, Elder et al. [14] conducted a randomized, double blind, repeatedmeasure, crossover trial evaluating the efficacy of GFCF diet in 15 children with ASD. Patients were on diet for 12 weeks. Group data indicated no statistically significant findings. In 2010, Whiteley et al. [15] enrolled 72 children with ASD who were randomly assigned to the GFCF diet or a control group. The overall attrition rate was high (11\%): at the 12-month follow-up only 28 children remained in the GFCF group and 29 in the normal diet. At the same time-point, while patients in the GFCF continued their diet until the end of the study, children eating a normal diet were switched to the GFCF (however, only if their outcome measures at 12 months exceeded a predefined, but unclear, threshold). At the 24-month follow-up only 18 children did not drop out from the GFCF diet. The authors assessed ASD symptoms at baseline and 8, 12, 20, and 24 months, through the Autism Diagnostic Observation Schedule-Generic (ADOS-G), the Vineland Adaptive Behavior Scale (VABS), and Gilliam Autism Rating Scale (GARS). It is unclear on what patient groups or time-points the statistical analysis was carried out. The authors reported a significant improvement in social symptoms (measured only with GARS) and communication and repetitive behavior (ADOS assessed). However, the observed differences did not seem clinically meaningful. In 2011, Johnson et al. [16] piloted a three-month, prospective, randomized, parallel group trial. Twenty-two children with ASD were randomized to the GFCF diet or a healthy, low sugar diet. No statistically significant differences in core symptoms were reported between GFCF diet and control diet. The GFCF diet did not determine more side effects than the healthy diet. Unfortunately, adherence to the GFCF diet proved to be difficult.

Among other less common dietary interventions for autism, the ketogenic diet should be mentioned. The ketogenic diet is low-carbohydrate, high-fat diet which has been successfully administered in children with refractory epilepsy: this dietary regimen determines a better seizure control and has an effect comparable to antiepileptic drugs [110]. Evangeliou et al. (2003) [17] conducted a prospective follow-up trial evaluating the use of the ketogenic diet in 30 children with ASD. The diet was based on the John Radcliffe diet, which consisted of the following regimen: $30 \%$ of energy derived from medium-chain triglyceride oil, $30 \%$ from fresh cream, $11 \%$ from saturated fat, $19 \%$ from carbohydrates, and $10 \%$ from protein. This dietary treatment appeared more easy to follow and manage than the proper ketogenic diet. The diet was administered for 4 weeks, followed by 2 weeks of normal nutritional regimen. This cycle was repeated for 6 months. Overall, twelve patients discontinued the diet. The subjects who completed the study reported at least a minor improvement in CARS scores. However, this study suffers from an unblinded design, a high drop-out rate, and a poor diagnostic characterization of the participants.

IgE and non-IgE-mediated food allergies are highly prevalent among children. Food allergy could determine the onset of different neuropsychiatric symptoms, such as hyperactivity, or worsen behaviors already present in young patients with ASD [111]. Moving from this hypothesis, Karkelis et al. (2010) [18] tested a new diet in which children were randomly assigned to an elemental formula (containing free amino acids-Neocate) diet with exclusion of all milk products or to their previous normal diet. Study participants were also subdivided according to the presence or absence of IgE for cow milk. After 4 months, the authors reported a significant reduction of hyperactivity.

Traditional Chinese Medicine (TCM) has been practiced in Eastern countries for over 2000 years. It is based on a unique theoretical approach to diagnosis and treatment. It works on balancing opposing energies (yin and yang) and the life force (qi), which are present in everybody. According to the National Center for Complementary and Alternative Medicine, TCM comprehends several practices "including acupuncture, moxibustion (burning an herb above the skin to apply heat to acupuncture points), Chinese herbal medicine, tui na (Chinese therapeutic massage), dietary therapy, and tai chi and qi gong" [112]. Among TCM diets, the Chanyi approach suggests to decrease the intake of some foods (like meat and fish, eggs, ginger, garlic, and onion) which are thought to produce higher internal heat and exert a negative impact on the child's mood and cognitive functions. Chan et al. [19] conducted a double blind randomized study in which 24 ASD children were assigned either to a specific diet modification based on the Chanyi approach or to their usual diet for one month. The authors observed a significant improvement in parent-rated social problems and repetitive behaviors.

To date, the only functional food tested in autism is camel milk. Camel milk contains less cholesterol and lactose than cow milk and more vitamins and enzymes such as the peptidoglycan recognition protein (PGRP), which plays a role in preventing food allergy and modulating the immune system [20]. Two placebo controlled double blind randomized trials $[20,21]$ showed significant improvement in CARS scores and in antioxidant activity in children treated either with raw or boiled camel milk for 2 weeks compared to placebo.

4.2. Nutraceuticals. The term nutraceutical is defined as "any substance that is food or a part of food and provides medical 
or health benefits, including the prevention and treatment of disease" [113]. Usually, nutraceuticals consist of dietary supplements (such as vitamins, minerals, amino acids, and herbal substances) or functional food. Nutraceuticals could represent a potential treatment for autism with limited or no side effects, and they are commonly used in families with ASD (Table 2) [8].

4.2.1. Omega 3. Among nutraceuticals, one of the most popular is omega 3 supplementation. Omega 3 fatty acids are essential polyunsaturated fatty acids, derived mainly from fish and seafood (the eicosapentaenoic acid (EPA) and the docosahexaenoic acid (DHA)) or seeds and grains (the alpha-linolenic acid (ALA)). The hypothesis behind the use of omega 3 in autism is still not completely formulated: it is, however, well known that omega 3 fatty acids are essential for brain development and function [114]. A recent Cochrane review [115] has meta-analyzed the findings of two randomized trials (total sample size $=37$ ) $[22,23]$, evaluating the effect of omega 3 supplementation compared to placebo in children with ASD. Omega 3 dosage varied from $1.3 \mathrm{~g} /$ day to $1.5 \mathrm{~g} /$ day. Supplementation lasted for six weeks [22] and 12 weeks [23], respectively. Both studies used at least one common outcome measure, the Aberrant Behavioral Checklist (ABC). Overall, there was no significant effect of omega 3 supplementation on social interaction, communication, stereotypy, or hyperactivity. From this metaanalysis only two double blind placebo controlled trials were published. In one study [24], the authors recruited 57 children with ASD who were assigned to $1.3 \mathrm{~g} /$ daily of omega 3 or placebo for six weeks. Parent-rated symptoms were evaluated through an Internet questionnaire each week. Study findings showed no significant difference between omega 3 supplementation and placebo. Recently, 48 children with ASD [27] were randomized in a double blind fashion to receive DHA ( $200 \mathrm{mg} /$ daily) or a placebo for 6 months. Outcome measures were the Clinical Global Impressions-Improvement scale, the Child Development Inventory, the $\mathrm{ABC}$, and the Behavior Assessment Scale for Children. No significant difference was reported between the two groups. Two nonrandomized studies $[25,26]$ showed contrasting results: however, several methodological flaws were present in each study and also type and dosage of omega 3 supplementation varied greatly between the trials.

4.2.2. Vitamins. Vitamin supplementation is another popular CAM therapy in ASD. The rationale for this treatment is based on the frequently observed dietary deficiency of vitamins and micronutrients in children with ASD. In fact, it has been reported that children with ASD introduce less than recommended amounts of calcium, vitamin $\mathrm{D}$, vitamin $\mathrm{K}$ [116], vitamin A, vitamin E [117], zinc, vitamin B6 [118], and tetrahydrobiopterin [119]. These deficiencies could be the result of food selectivity or altered gastrointestinal absorption [118]. Several trials evaluating vitamins supplementation in ASD have been conducted. A recent Cochrane systematic review [120] evaluated the efficacy of combined vitamin B6magnesium supplementation in ASD. The use of vitamin B6 moved from early data (1968) showing language improvement in autistic children treated with this nutraceutical. The combination of vitamin B6 with magnesium was postulated as magnesium could counteract several side effects connected with B6 supplementation (such as enuresis and irritability) [120]. Three randomized controlled studies were included [28-30], but data could not be meta-analyzed due to substantial heterogeneity between the trials. It is of note that all three trials reported no statistically significant difference between vitamin B6 supplementation and placebo. However, results could not be regarded as conclusive because several limitations in the study design should be taken into consideration such as small sample sizes and flawed data reporting.

Vitamin B12 was tested in two trials: the first from Bertoglio et al. [31] was a double blind, placebo controlled, randomized, crossover trial evaluating methyl B12 alone in children with ASD. The authors did not observe any significant difference between active treatment and placebo. However, in a post hoc analysis they were able to identify a subgroup of patients (30\%) which could be rated as clinically improved after the active treatment but not after the placebo. Subsequently, Frye et al. [32] conducted an open label trial in which children were administered methyl B12 and folinic acid for three months. The authors reported a significant improvement in Vineland total and subscales score. However, given the study design, no precise conclusion could be drawn from the findings; additionally the authors included only patients with abnormal redox metabolism which could in turn limit the generalizability of the results to the entire ASD population. Furthermore, methyl B12 is administered through injection, a procedure which could be uncomfortable for children and adults with ASD: this fact could potentially explain the high drop-out rate (almost $25 \%)$.

Vitamin C supplementation alone is not so common in ASD. However, Dolske et al. [33] observed a reduction in stereotyped behaviors in a 30 -week, double blind, placebo controlled trial in 18 children with ASD.

Multivitamin supplements were tested in a double blind randomized trial [121]. A common commercial vitamin supplement (containing several vitamins, minerals, no copper and iron, and antioxidants such as coenzyme Q10 and nacetyl cysteine) was chosen as active treatment. The authors recruited 141 children with ASD who were randomly assigned to active treatment or placebo. The dosage was adjusted according to the child's weight and titrated to the full dose in three weeks. Supplementation lasted for three months. The authors observed improvement in parent-rated scores of irritability. However, the study suffered from a poor characterization of participants, which could be on psychotropic medications and put on different elimination diets. Additionally, the use of a multivitamin supplement prevented identifying single contributions of different vitamins and minerals.

Tetrahydrobiopterin (BH4), as other vitamins and micronutrients, is a natural substance that plays an essential role in several biochemical pathways. It has been tested as a therapeutic treatment in ASD in three trials. The first from 


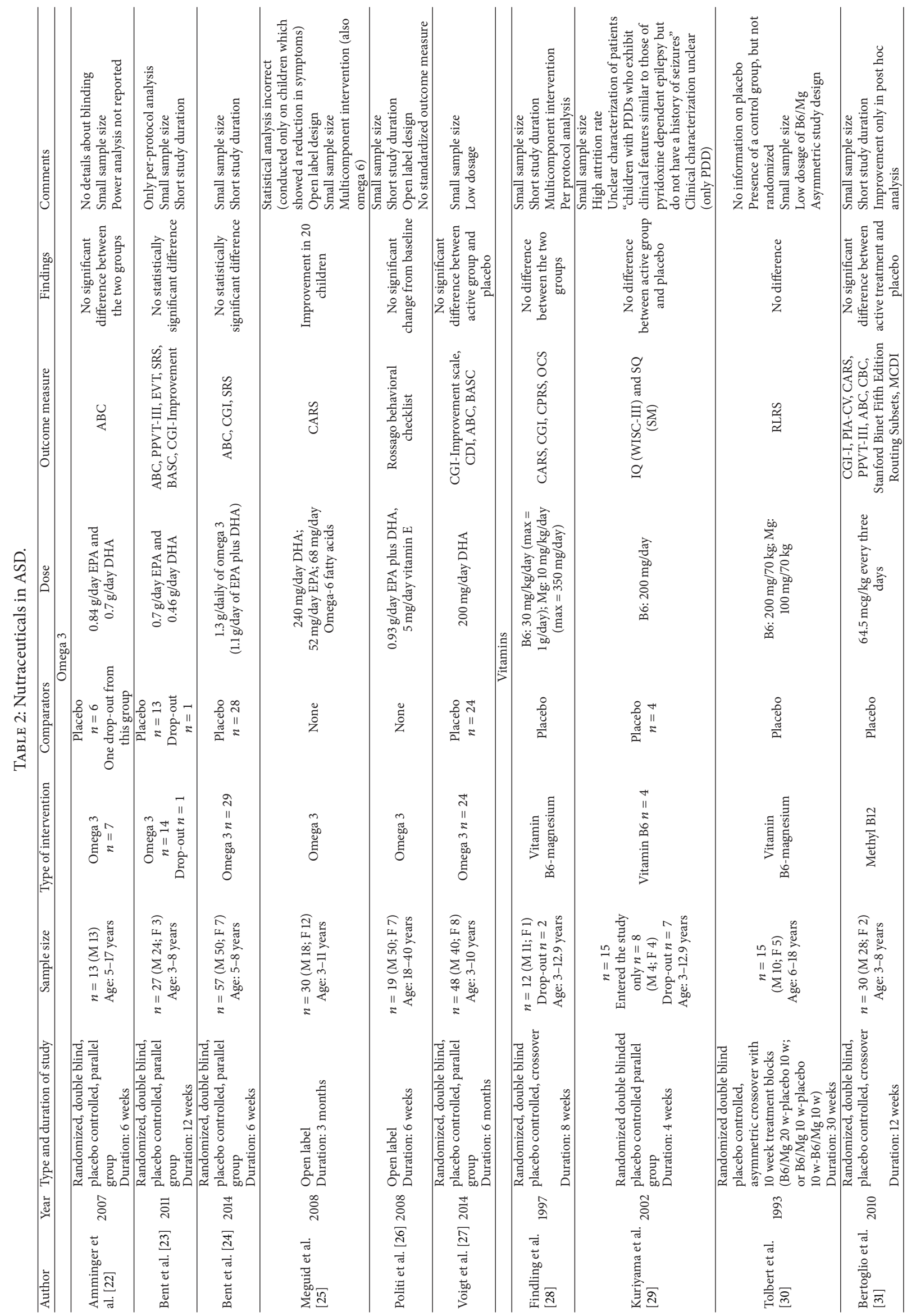




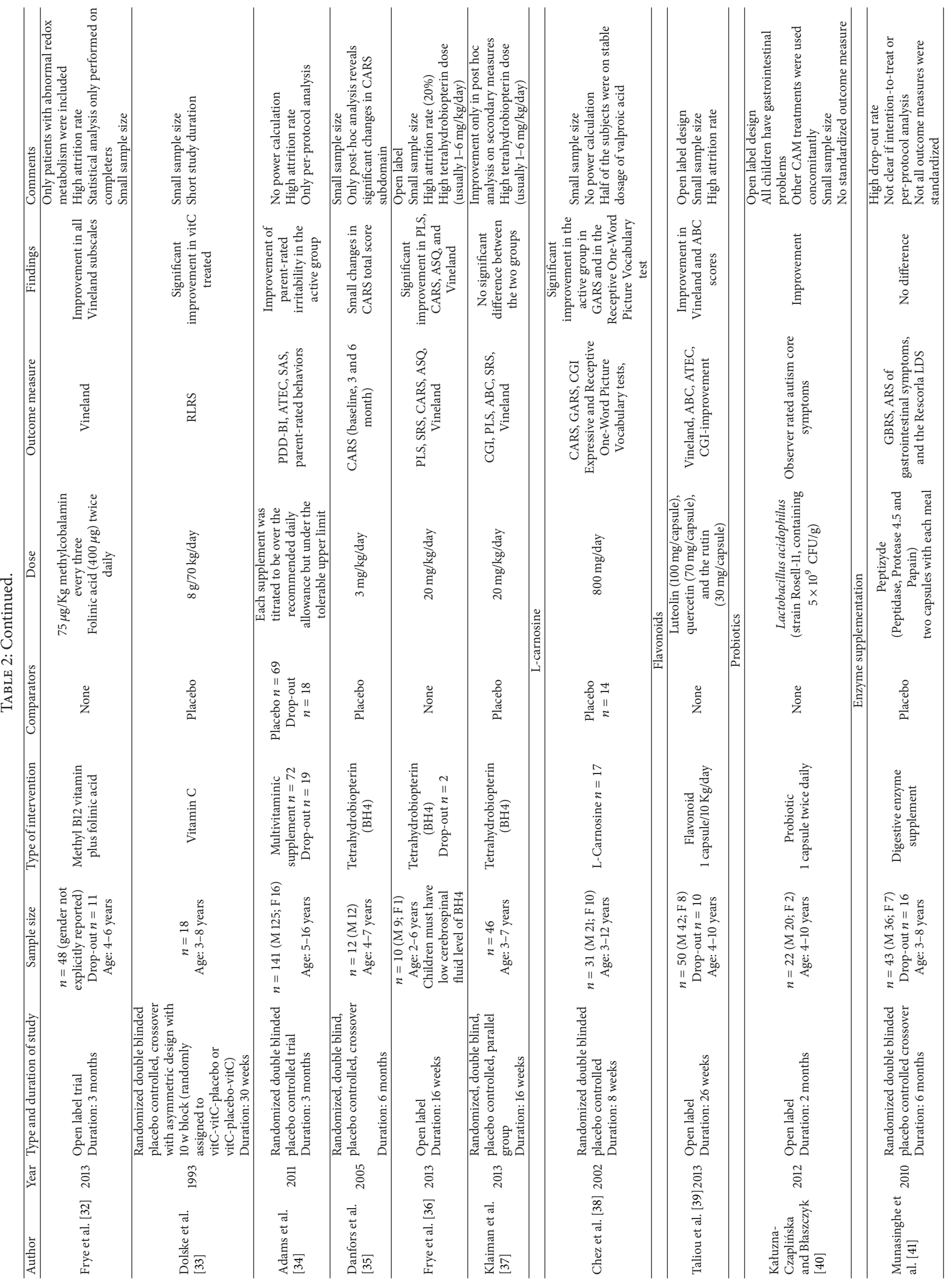




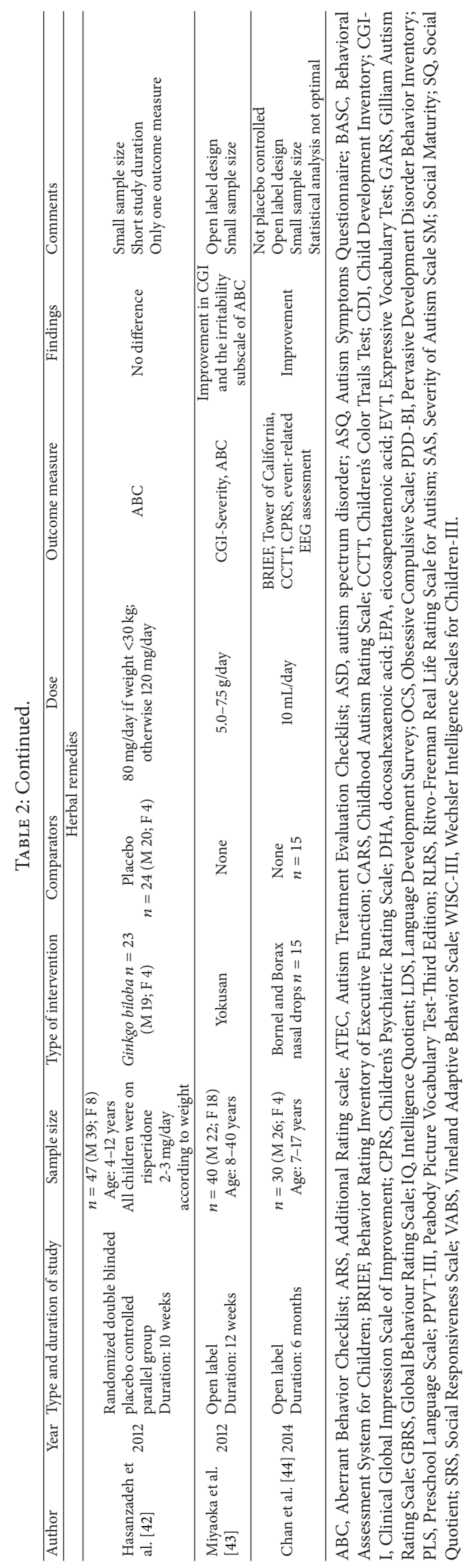


Danfors et al. [35] was a randomized, double blind, placebo controlled, crossover study. Children with ASD were randomized to either $\mathrm{BH} 4$ or placebo for three months and then switched for other three months. No significant change was detected; only post hoc analysis revealed minor changes in secondary outcome measures. On the other hand, more recently, an open label trial [36] was aimed at testing $\mathrm{BH} 4$ in children with ASD and low cerebrospinal fluid level of $\mathrm{BH} 4$. The authors observed significant changes in several outcome measures on language production, social communication, activity of daily living, and irritability. However, the sample was very small and $\mathrm{BH} 4$ dosage was very high compared to previous reports [35]: it is of note that only $20 \%$ of subjects reported adverse events such as insomnia, irritability, and mild stomach discomfort. Another recent double blind, randomized, placebo controlled study [37], using a protocol similar to a previous study [35], did not report improvement in the primary outcome measure (Clinical Global Impression-Improvement and Severity): however, post hoc analysis on secondary outcome measures showed improvement in the $\mathrm{BH} 4$ group in social awareness and reduction of hyperactivity, mannerisms, and inappropriate speech.

4.2.3. L-Carnosine. L-Carnosine is another CAM therapy tested in autism. The rationale for the use of this nutraceutical relies on the connection between carnosine and GABA functioning, which seems to be altered in ASD [122]. In particular carnosine could alter neurotransmission by interacting with zinc and copper at GABA receptor level [123]. In the only double blind, placebo controlled, randomized study [38] conducted so far, $400 \mathrm{mg}$ of L-carnosine were administered twice daily to 17 children with ASD, while 14 children received the placebo. The follow-up lasted for 8 weeks. The authors found that supplementation with carnosine improved receptive speech and social behavior, with no side effect (apart from rare hyperactivity which disappeared after lowering the dose). It is of note that change in Clinical Global Impression rating did not reach significance, thus reducing the validity of the results.

4.2.4. Flavonoids. The presence of altered redox status and concomitant subclinical inflammation has been reported in ASD [124]. Natural flavonoids, in particular quercetin and luteolin, exert a powerful antioxidant activity and have a low redox potential which could in turn be useful in autism [125]. Unfortunately, only one open label prospective trial [39] has evaluated a formula containing luteolin (100 mg/capsule, from chamomile), quercetin (70 mg/capsule), and the quercetin glycoside rutin $(30 \mathrm{mg} /$ capsule $)$ in 50 children with ASD. Only 40 subjects completed the 26-week follow-up. Significant changes in adaptive functioning and aberrant behaviors were observed. The most relevant adverse event was irritability, which was experienced by half of the sample usually at the beginning of therapy (1-8 weeks).

4.2.5. Probiotics. According to the World Health Organization, probiotics are live microorganisms which could exert health benefits on the host. Generally, probiotics are bacteria which belong to two groups, Lactobacillus or Bifidobacterium spp. In recent years, the gut-brain connection in autism has obtained much relevance: in fact, it is well known that gastrointestinal tract and brain can influence each other. Particularly, gut inflammation or altered microflora could determine a detrimental effect on brain development and function [126]. Moving from these premises, in 2012, 22 children with ASD were recruited in an open label trial [40]. They received two capsules daily of Lactobacillus acidophilus for two months. The authors observed significant modification in urinary excretion of arabinol and, concomitantly, significant improvement in core symptoms of autism, such as eye contact and correct recognition of human emotion.

4.2.6. Digestive Enzymes. Moving from the hypothesis of gut abnormalities in autism, a double blind, placebo controlled, randomized, crossover trial has evaluated supplementation with digestive enzymes in autism [41]. The supplement was composed of three plant-derived enzymes (peptidase, protease 4.5, and papain) and was administered for three months; the active phase was preceded/followed by a placebo phase of the same duration. Of the 43 children enrolled, 16 did not complete the trial. Overall, there was no significant clinical change in autistic symptoms between enzyme treatment and placebo. It is of note that the authors observed that patients on the active treatment displayed higher food variety.

4.2.7. Herbal Remedies. Among herbal remedies, a recent study from Chan et al. [44] investigated the potential usefulness of intranasally administered Borneol and Borax (two herbs which in Chinese traditional medicine were thought to enhance cognitive abilities) in 15 children with ASD. They recruited additionally 15 children with ASD which acted as a control group. This pilot study lasted for six months. The authors reported that subjects in the experimental group showed more flexibility in problem solving, greater attention, and planning capacities. Yokukansan, a traditional Japanese herbal remedy used for restlessness and behavioral symptoms of dementia, was tested in a 12-week, open label trial [43] in which the herb was administered to 40 subjects with Asperger syndrome or PDD-NOS. The dose was gradually titrated from $2.5 \mathrm{~g}$ /day to a maximum of $7.5 \mathrm{~g} /$ day. $90 \%$ of the sample showed a clinically significant response, and no serious adverse event was reported (only mild nausea in five patients). Ginkgo biloba, which could exert a useful anti-inflammatory activity and potentially enhance cognitive function [127], was evaluated in a study involving 47 children with autism [42]. Patients were randomly assigned to either Ginkgo biloba or placebo in adjunction to risperidone. The primary outcome was the ABC scale. There was no statistically significant difference between the two groups according to the aforementioned subscale. Thus Ginkgo biloba did not seem to be an efficacious adjunctive therapy to risperidone. However, it appeared to be safe and well tolerated even in childhood. 
4.3. Hyperbaric Oxygen Therapy. Hyperbaric Oxygen Therapy (HBOT) is generally used to treat carbon monoxide poisoning or air embolism. The exact mechanism of action is not yet fully understood but HBOT seems to exert positive effects on different neurological symptoms $[99,128]$. HBOT has been tested in four different trials with inconsistent results (Table 3). Particularly, two well-designed, randomized trials yielded opposite findings: Rossignol et al. [47] showed significant improvement while Granpeesheh et al. [45] observed no difference between the active and control conditions. Both studies were well conducted with good characterization of the participants and intention-to-treat analysis. However, the study from Rossignol et al. suffered from the absence of a placebo condition because it compared two different HBOT procedures. Recently, in 2012, another randomized trial [48] (which has a lower quality) has reported no significant difference between HBOT and a sham condition (with high pressure, but no supplemental oxygen). It is of note that both groups seemed to improve from baseline. A small open label trial reported improvement in several symptoms of ASD [46].

4.4. Chelation. Chelation treatment involves administration to an individual of various chemical substances for the purpose of binding and then withdrawing specific metals from the person's body [98]. Chelation in ASD has been investigated in a few studies collected in a review published in 2012 [129]. The review included 5 studies for a total of 82 participants. However, for the purpose of the present review, only the study from Adams et al. [49] and from D. A. Geier and M. R. Geier [50] could be included (the others were case report or case series) (Table 4). Adams et al. [49] conducted a double blind, randomized trial which did not demonstrate any significant evidence supporting the utility of chelation treatment in ASD. D. A. Geier and M. R. Geier [50] designed an open label trial in which children underwent chelation and antiandrogen therapy. The authors reported significant improvement, but the study design and the multicomponent intervention refrained to draw solid conclusions.

\section{Nonbiologically Based CAM Treatments}

The National Center for Complementary and Alternative Medicine (NCCAM) divides nonbiological CAM therapies in three groups: mind-body medicine (i.e., prayer, yoga, meditation, music, dance, and art in general), manipulative and body-based practices (i.e., massage, chiropractic care, and acupuncture), and energy medicine (i.e., Reiki or homeopathy) [112].

5.1. Music Therapies. Music therapy can be defined as "a systematic process of intervention wherein the therapist helps the client to promote health, sing musical experiences and the relationships that develop through them as dynamic forces of change" [130]. The role of music therapy as a treatment for several psychiatric conditions (i.e., depression, schizophrenia, substance dependence and abuse disorder, and dementia) has been studied for many years, because of its effectiveness in the domains of physical recovery, cognitive improvement, communication skills, and social and emotional rehabilitation [131]. Musical improvisation in autism could represent a sort of nonverbal shared language that could enable both verbal and nonverbal patients to reach communication [132]. In fact, it has been reported that the learning of language in infants is highly based on the musicality of sounds [133]. Additionally, children with ASD appeared to respond better to music than to spoken words [134]. As a hypothesis, because different brain regions processed music or words [133], the use of song could help people with ASD to understand emotion which they have difficulties in detecting in words.

The use of music therapy in the treatment of ASD patients has been tested in several studies (Table 5). In 2014 [135], the Cochrane Collaboration reviewed 10 randomized controlled trials (RCT) which have been published from 1995 to 2012 [51-60]. Considering all studies, total sample size was 93. The findings provided evidence that music therapy may help children with ASD to improve their skills in primary outcome areas like social interaction, verbal communication, initiating behavior, and social-emotional reciprocity. It may also help to enhance nonverbal communication skills within the therapy context. Furthermore, it may contribute to increasing social adaptation skills in children with ASD and to promoting the quality of parent-child relationships. However, several included studies suffered from a very small sample size and from difficulties in defining a standard in music therapy methodology in order to facilitate replicability. From this review, no other RCT have been published. We retrieved also two open label trials. Firstly, Boso and colleagues experimented music therapy in 8 adults with ASD. The study showed significant improvement in several standardized scales (CGI-S, CGI-I, and BPRS) [61]. Another recently published study included 10 patients. Iseri and colleagues did not find any change in hormonal levels but improvements in patients' behavior, social, and communication skills [62].

Other types of music-related therapies have been investigated in ASD, which involved music as an active part of the intervention. Kalas [63] tried to elicit responses to joint attention in 30 autistic children with ASD by making them listen to two different types of music (simple and complex). The cohort was divided into two groups of severity and the study demonstrated that while simple music was more effective in severe ASD patients' joint attention, complex music was more effective in children with mild or moderate autism. The main flaw of this study was the lack of a standardized outcome measure. Vibroacoustic music has been investigated in individuals with mental retardation and also in a small sample of patients affected by autism [64]. The randomized study was focused on self-injuring, aggressive and stereotypical behavior and demonstrated that vibroacoustic music may be useful in reducing these aspects. We have to underline that the study is not specific for ASD and that the experimenters did not account for possible confounders. Schwartzberg and Silverman [65] evaluated the social skills profile in children with autism in a threeweek study. Children were divided into two groups: in one group the children were sung social stories, while in the other group the stories were simply read. Unfortunately, no 


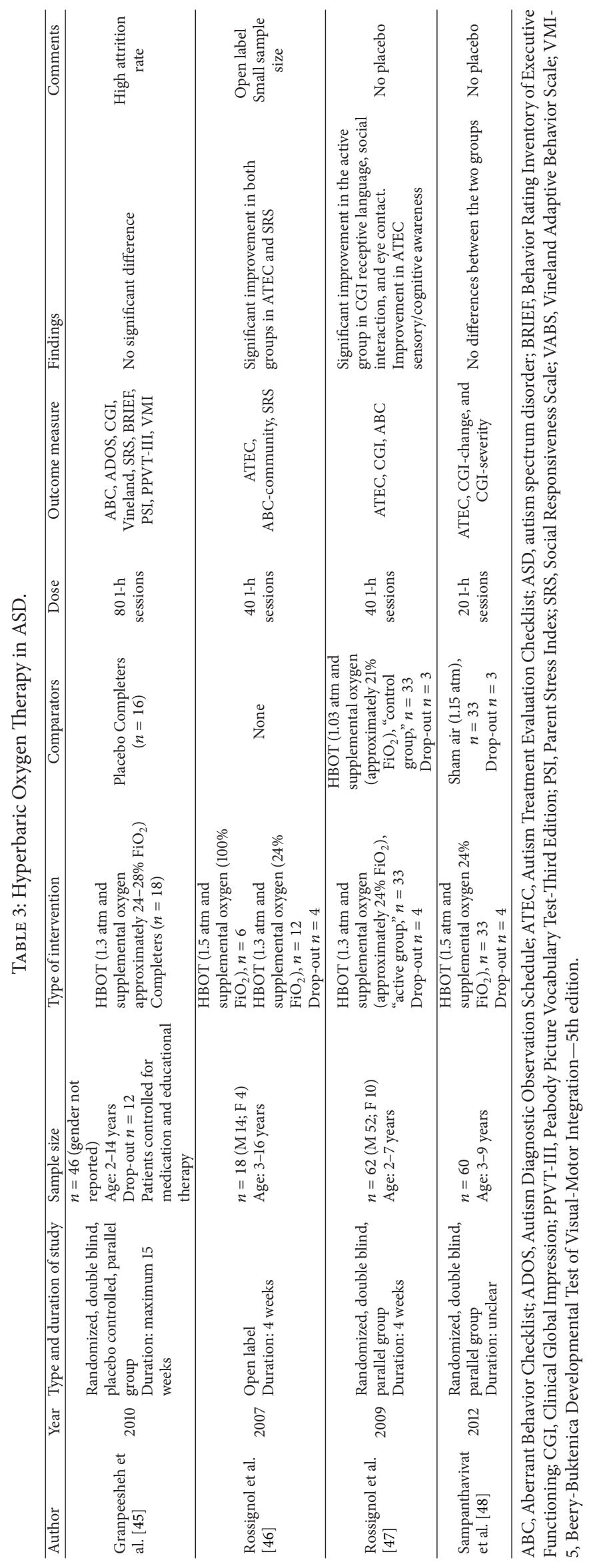




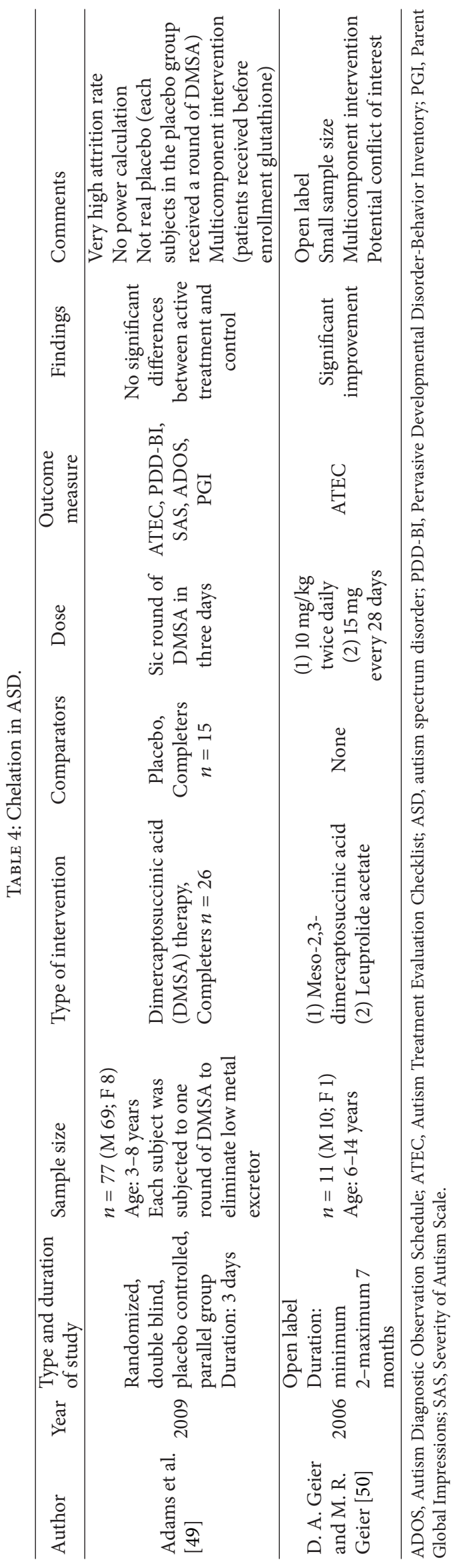




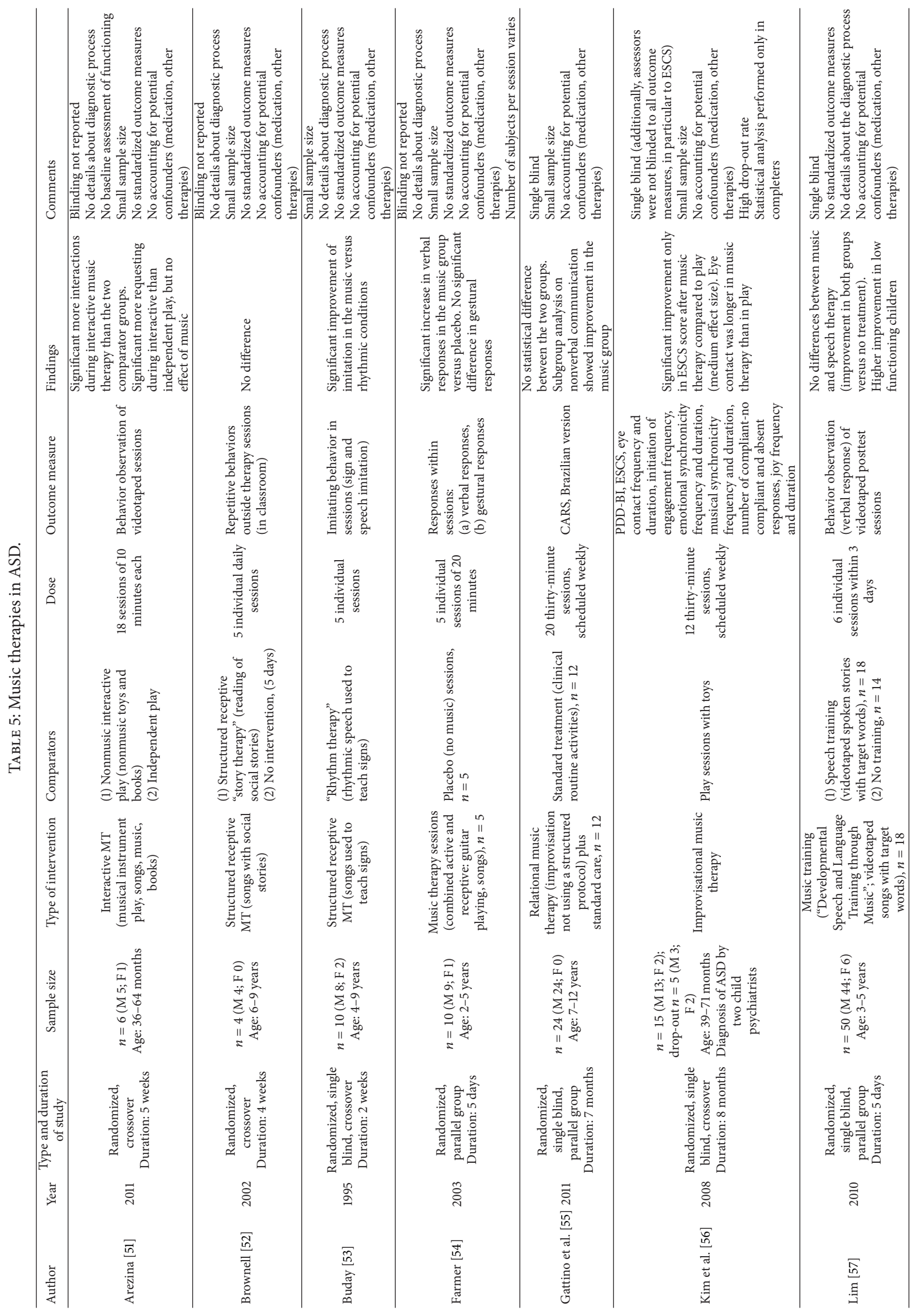




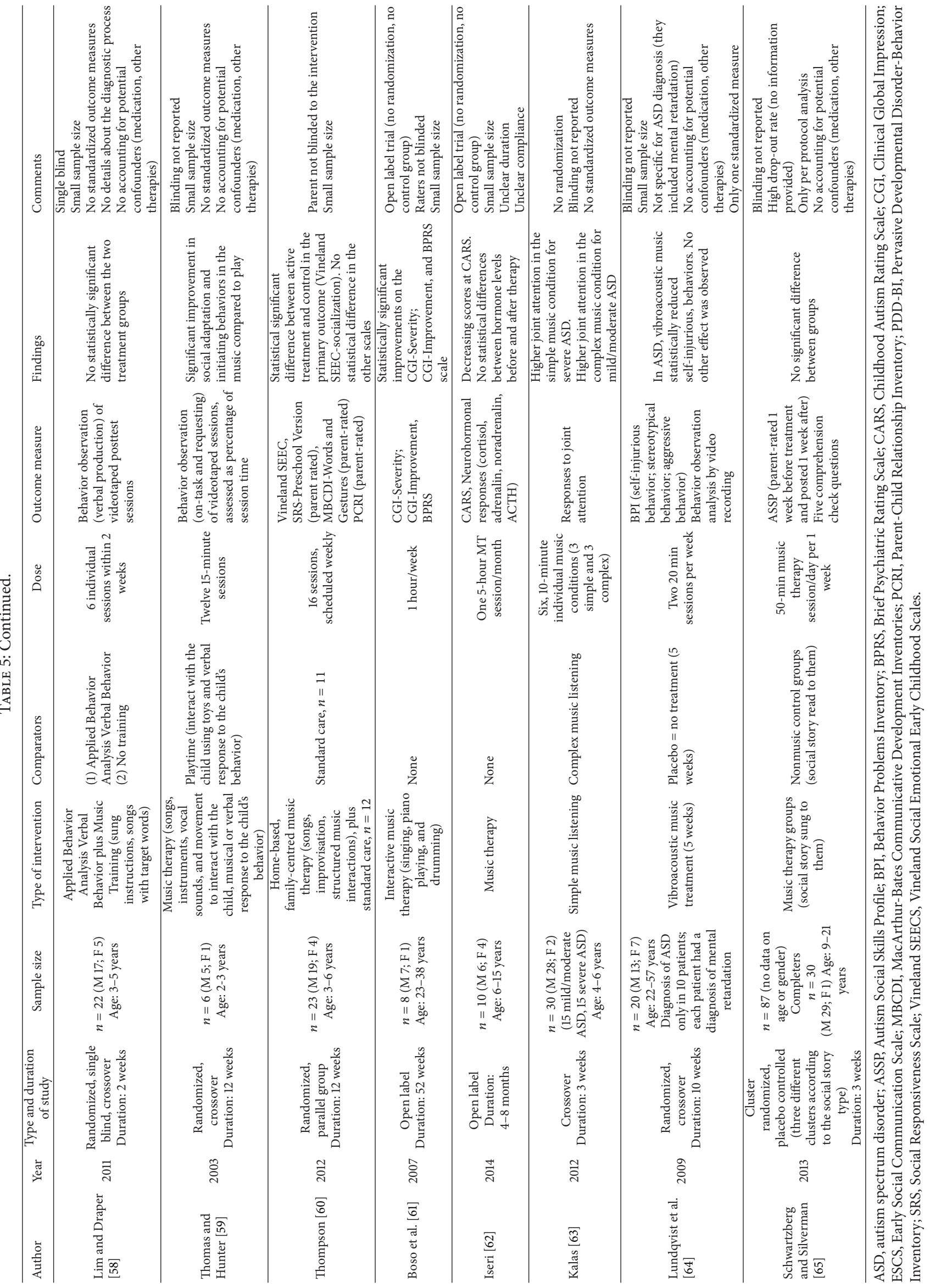


significant differences between the two groups have been found. As in the previous studies, blindness is not reported. In addition, the drop-out rate is quite high and the authors only performed a per-protocol analysis.

\subsection{Auditory Integration Training. Auditory Integration} Training (AIT) involves a person listening to a selection of music which has been electronically modified. There are several kinds of AIT including the Berard Method, the Listening Program, the Samonas Sound Therapy, and the Tomatis Method [136]. AIT is based on the idea that some people, including some people with autism, are hypersensitive or hyposensitive to certain frequencies of sound. AIT is designed to improve the person's ability to process sounds by "re-educating" the brain [136].

The Cochrane Collaboration recently published a systematic review [136] that collects the main publications in this field of research (Table 6). Six relatively small studies [66-71] were included. All the experimental groups underwent two 30 min sessions of AIT for 10 consecutive days. The largest studies did not report a difference between treatment and control conditions and in one case there is no evidence for long-term benefits of AIT. These studies contained several flaws, like small sample sizes, wide range of participants' baseline characteristics (age and sex), unstandardized outcome measures, and blinding.

5.3. Sensory Integration Therapy. Individuals with ASD often display impairments in sensory information processing. As a result, situations involving contact with lights, sounds, smells, tastes, or textures could be overwhelming for patients [137]. Sensory integration therapy commonly uses play activities specifically studied to modulate how the brain responds to sight, touch, sound, and movement [138]. Even if common among families with an ASD child, its results have been controversial. We retrieved four trials [72-75] (Table 7). All studies yielded significant improvement in several autistic core symptoms (communication, social reciprocity, and motor activity). However, only two studies used a standardized form of sensory integration therapy to allow replicability. Additionally, only half of the trials used standardized outcome measures, while the others were based on direct observation of behaviors or ad hoc questionnaire. Another potential bias to consider is the lack of well-defined control group (some trials used fine motor activities such as tapping but with no additional details).

5.4. Drama Therapy. Drama represents a form of art, which could foster the development of social skills (i.e., pretention, communication, social reciprocity, and emotion recognition). Drama therapy may therefore represent a potential therapy for individuals with ASD [139]. In particular, one open label study (Table 8) investigated a specific form of theatrical therapy-SENSE (Social Emotional NeuroScience Endocrinology) theatre-specifically designed to ameliorate social functioning and stress in children with ASD [76]. The authors enrolled 8 autistic children and 8 matched normally developed subjects who would act as models for the ASD patients. The authors observed a mild improvement in Theory of Mind (ToM) skills and facial emotion recognition. Unfortunately, this study suffered from several flaws: the study design, the lack of a control group, and the small sample size.

5.5. Dance Therapy. Dance and movement therapy is an embodied treatment that uses mirroring of movements: each subject tries to mirror empathic movements of the therapist, focusing more on "attunement" than on simple imitation. This may represent the basis for more mature form of social reciprocity [140]. Mateos-Moreno and Atencia-Doña [77] (Table 8) evaluated the efficacy of a combination of dance/movement and music therapy in 8 children with ASD. The active group was compared to a control group: each participant additionally received specialized treatment for ASD (i.e., behavioral and pharmacological therapy). Both groups improved over time with a better profile for the active group. However, given the multicomponent intervention, it is difficult to define the single contribution of dance therapy. Additionally, this study presented several flaws: the open label design, the nonrandom selection of subjects, and the small sample size.

5.6. Acupuncture. Acupuncture (AP) is a form of Traditional Chinese Medicine [112], widely used also in Western countries. It consists in placing needles in the skin and near tissues in specific points, known as acupuncture points. The needle could convey also electricity (electro-AP) or laser or heat. Four randomized controlled trials were retrieved according to our inclusion criteria (Table 9). The first (2008) [78] used scalp acupuncture (which involved needles to be placed in specific locations such as ear, nose, hand, and foot). The authors randomly assigned 10 children to group A (language therapy without scalp acupuncture) and 10 children to group B (language therapy plus scalp acupuncture twice weekly for 9 months for a total of 50 sessions). Even if the authors observed an improvement in both groups in language, no statistical analysis comparing the two groups was performed. In 2009, seven-star needle stimulation (which used a dermatoneural hammer housing seven blunt needles forming the shape of a seven-point star) was tested in 16 children with ASD [79]. The investigators observed a significant improvement in EEG pattern and in parent-rated language and social communication. However, parents were not blinded to the intervention and each child was attending educational therapy as well. In 2010 two studies were designed and conducted. The first [80] enrolled 55 children with ASD who were assigned to either electro-AP plus conventional treatment or sham electroAP plus conventional treatment for 4 weeks. There was an improvement in the Clinical Global Impression of change and in parent-rated score of social isolation, language, attention, and motor skills. Later on, the same author [81] randomized 50 children to tongue AP or sham tongue AP for 8 weeks. A significant improvement in the active group was reported. It is of note that the sham AP consisted in placing needles in nonacupuncture points and in the first trial by Wong and 


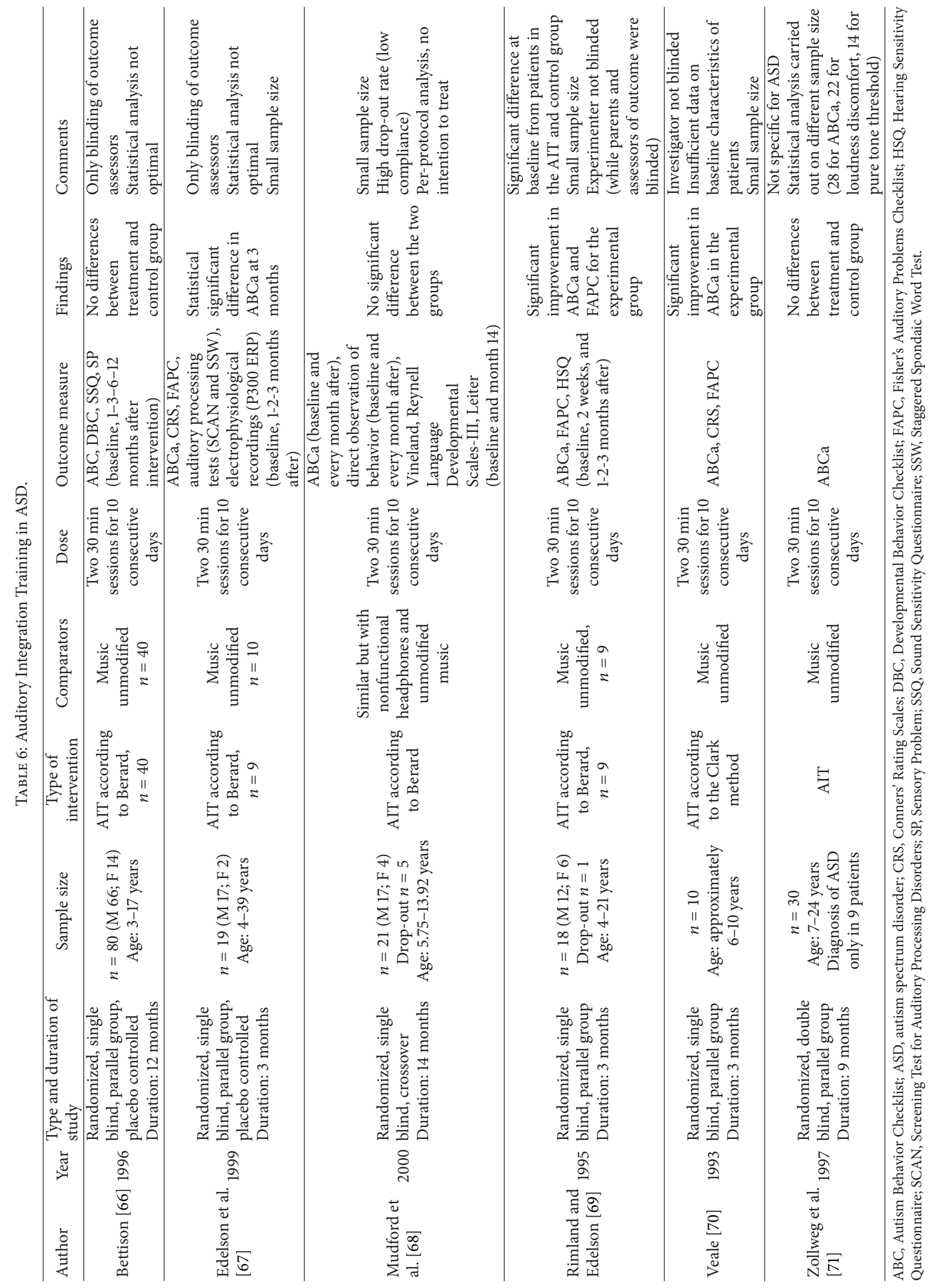




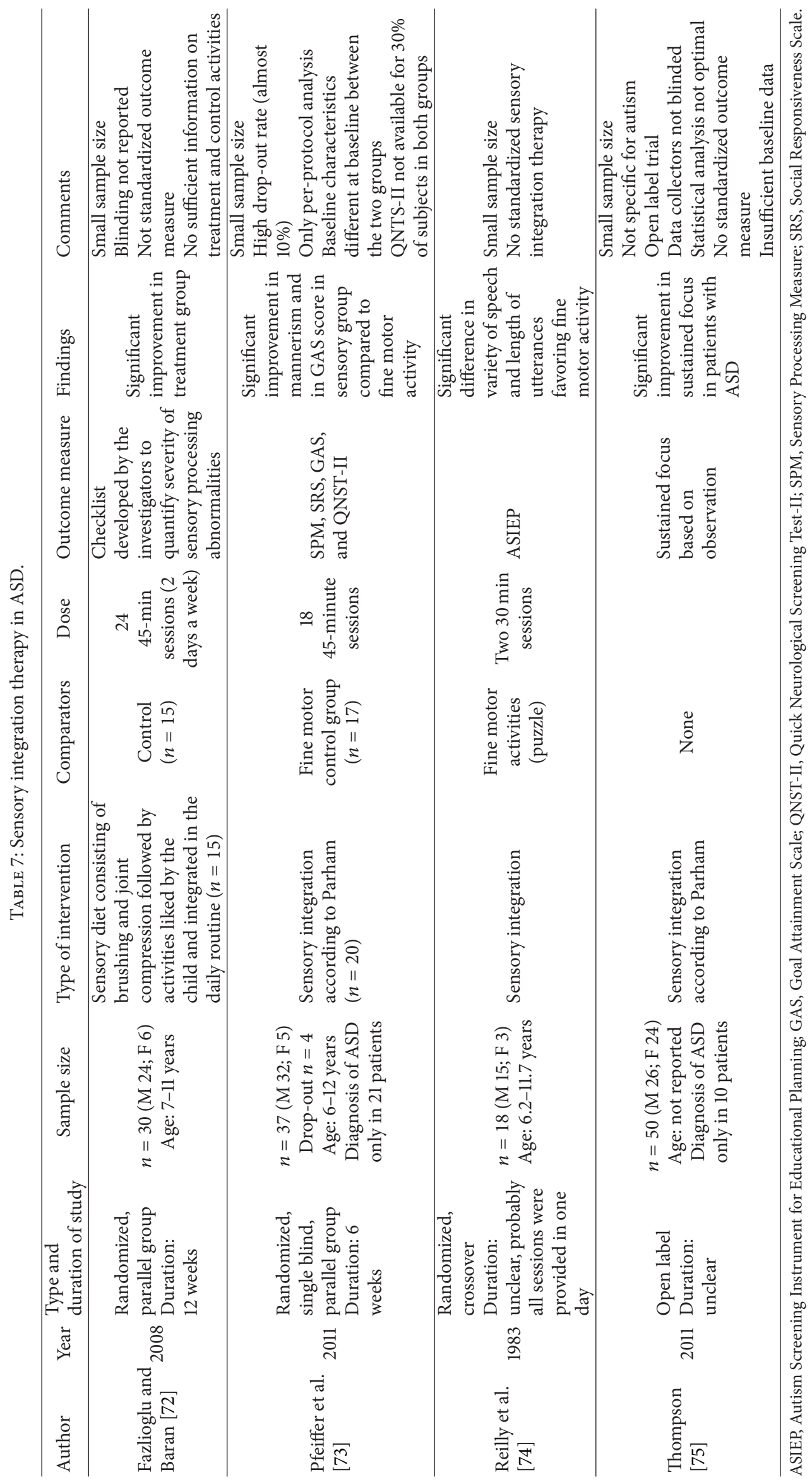




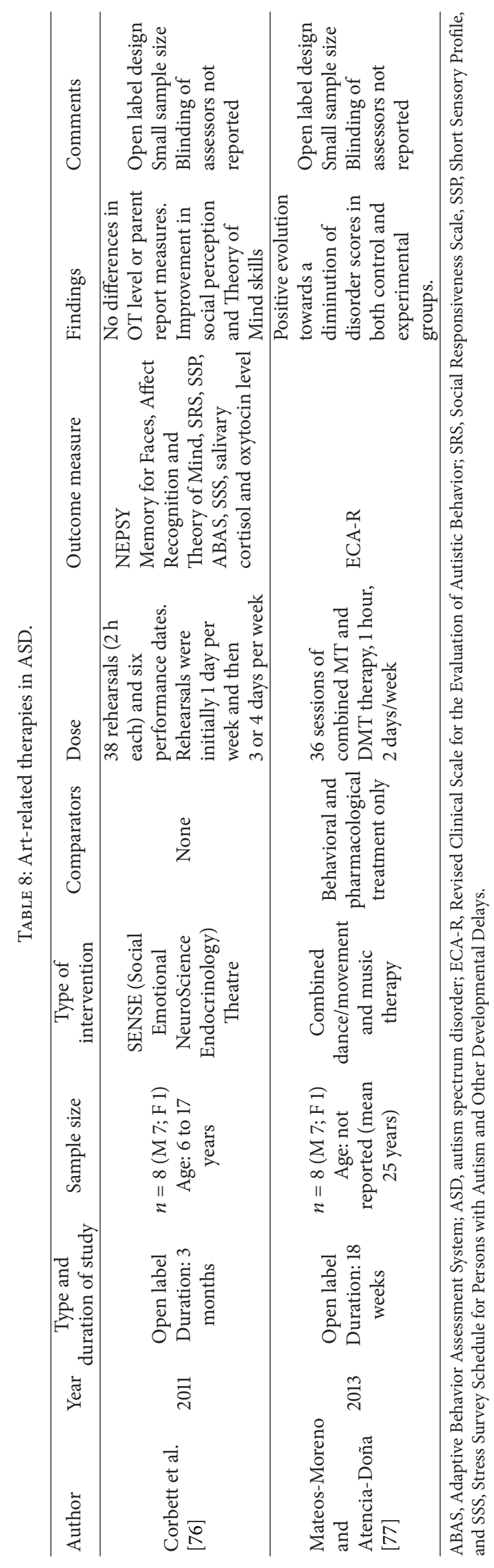




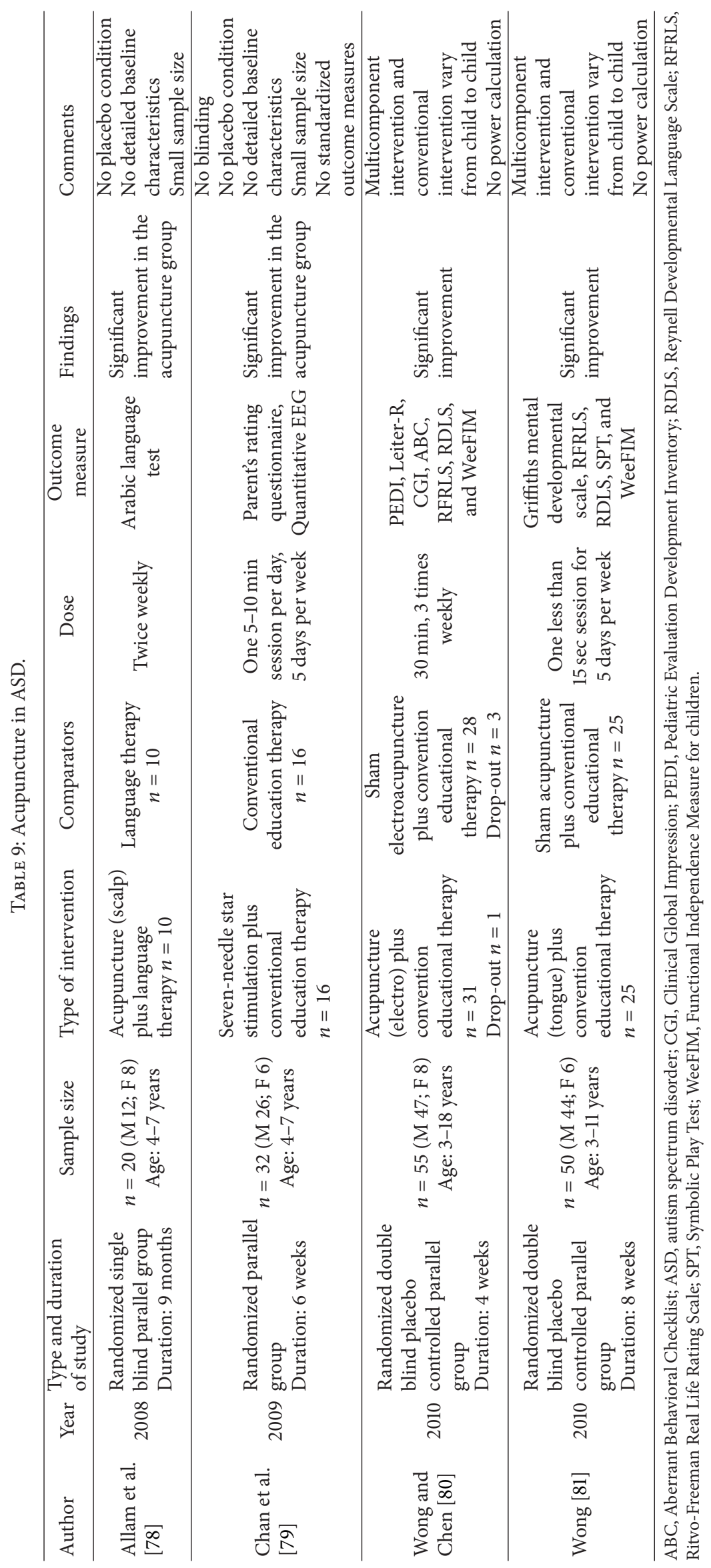


Chen sham AP also conveyed an electrical stimulation (so it was not properly sham).

5.7. Massage. Sensory hypo/hypersensitivity has become a symptom criterion for the diagnosis of ASD in the DSM-5 [141]. The use of touch in order to treat sensory impairment and reducing anxiety has been postulated in ASD [142]. A systematic review has recently investigated the effect of massage in ASD [143]. We retrieved four single blind, randomized trials which examined different types of massage (from simple touch to Thai massage) (Table 10). One study did not use standardized measures of outcome. Among the others, the brief report from Escalona et al. [82] involved 20 children who were assigned to touch therapy (15 min daily) provided by parents at bedtime or a control group (parents read bedtime stories to their child) for one month; the touch group showed improved social relatedness and a reduction in stereotyped behaviors. Two studies from Silva et al. [83, 84] evaluated a massage technique (the Qigong, consisting in massage manipulation from head to foot along acupuncture channels, lasting for 15 minutes). The first report [83] involved 13 children with ASD, randomly assigned to Qigong daily for five months plus a special education program or to the special education program alone. Children in the active group showed significant improvement in sensory impairment and Vineland Daily Living and Socialization subscores compared to controls. The second randomized trial [84] involved a larger sample with the same study protocol. Significant increase in socialization and communication and a reduction of sensory impairment were observed. More recently, another type of massage therapy (Thai massage) [85] was randomly administered to 60 children with ASD. The active group received Thai massage plus sensory integration therapy while the control group underwent sensory integration therapy alone. Thai massage was provided twice weekly for 8 weeks. At the end of the trial, the Thai massage group showed reduced anxiety and conduct problems measured through standardized parent-rated scales.

5.8. Yoga. Yoga is a movement therapy which could potentially ameliorate behavioral problems and anxiety (Table 11). It is of note that yoga appears to increase GABA brain levels, even after one session [144]. As GABA is considered to play a key role in autism pathogenesis, yoga may in theory represent a potential treatment candidate. In 2011, Rosenblatt et al. [86] conducted a pilot study in which they investigated combined yoga, dance, and music therapy in 24 children with ASD. The program consisted in 8 sessions of this technique: study findings showed no significant difference in the primary outcome measure-the Aberrant Behavioral Checklist (ABC) Irritability subscale. In 2012, a school based "get ready to learn Yoga" program was tested for efficacy in 48 children with autism [87]. The intervention was a manualized yoga technique performed by the teachers daily for 16 weeks, while the control group attended standard school morning activities. The authors found a significant reduction in teacher-rated $\mathrm{ABC}$ scores in the intervention group. Another movement therapy consisted in a mind-body exercise: 46 children with ASD were randomly assigned to either active treatment (Nei Yang Gong, a Chinese technique which "emphasizes the maintenance of a natural and relaxed attitude to achieve smooth circulation of Qi and blood" and involved "simple body movement" which has to be performed in a "relaxed and natural manner") or control treatment (Progressive Muscle Relaxation) [88]. Overall, the Nei Yang Gong session lasted for 5 minutes, while the control treatment session lasted for 20 minutes and were done twice per week for four weeks. Each participant was advised to practice also at home. Study findings reported increased self-control, reduced parent-rated autistic symptoms, and increased control of disruptive behaviors. In the Nei Yang Gong group, subjects displayed greater EEG activity in the anterior cingulate cortex.

5.9. Pet Therapy. The use of animals in ASD relies on the hypothesis that animal movements and behaviors are more predictable and repetitive and could help children with ASD to interpret social cues even in more subtle contexts (Table 12) [145]. The first studies conducted on pet therapy used dogs but were flawed by the absence of any type of standardized clinical measure or a lack of diagnostic characterization of subjects. Later on, more methodologically sounded trials were designed: in 2011, equine-assisted pet therapy was evaluated with an open label, prospective trial [89]. Twentyfour children with ASD entered a 3-to-6-month waiting list and subsequently switched to the horse riding treatment for 6 months. Only twenty children completed the trial. The results showed a significant reduction of CARS scores during the riding period compared to the waiting list. In 2014, Guinea pigs were used with 64 children with ASD [90]. The study has a nested design (classrooms in schools) and the animal therapy group was compared to the waiting list. The authors reported significant improvement in social functioning compared to the control situation.

5.10. Chiropractic Care. Chiropractic care is a popular and widely used CAM in ASD [146]. Its use in patients with ASD has been considered in a systematic review written by Alcantara et al. [147]. Beside three case reports, the review contained one cohort study [91] and one randomized comparison trial [92] (Table 13). In the first study, a cohort of 26 autistic children received chiropractic care for 9 months. Behavioral symptoms, based on parent and teacher assessments, improved. Additional improvements included decreased medication use. However, this study presents several biases, first of all the lack of a control group and the small sample size. The experiment conducted by Khorshid and colleagues compared two different types of chiropractic care: the Atlas Orthogonal Upper Cervical Spinal Manipulative Therapy (which is a form of chiropractic manipulation involving the instrumental percussion of the atlas to correct possible misalignments) versus full-spine Spinal Manipulative Therapy (which is characterized by high velocity and low amplitude thrusts) in children with autism. The major improvement was found in the Atlas Orthogonal 


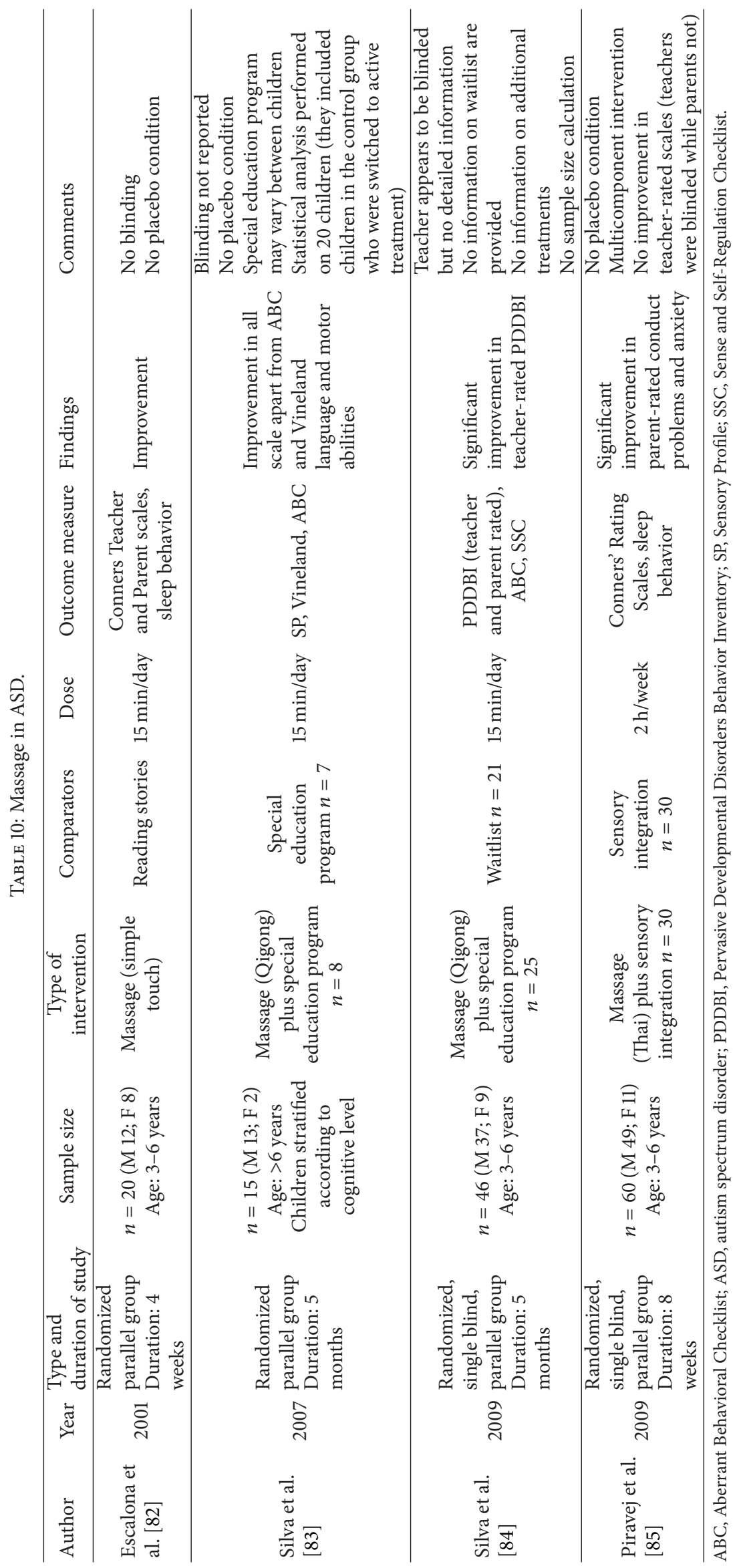




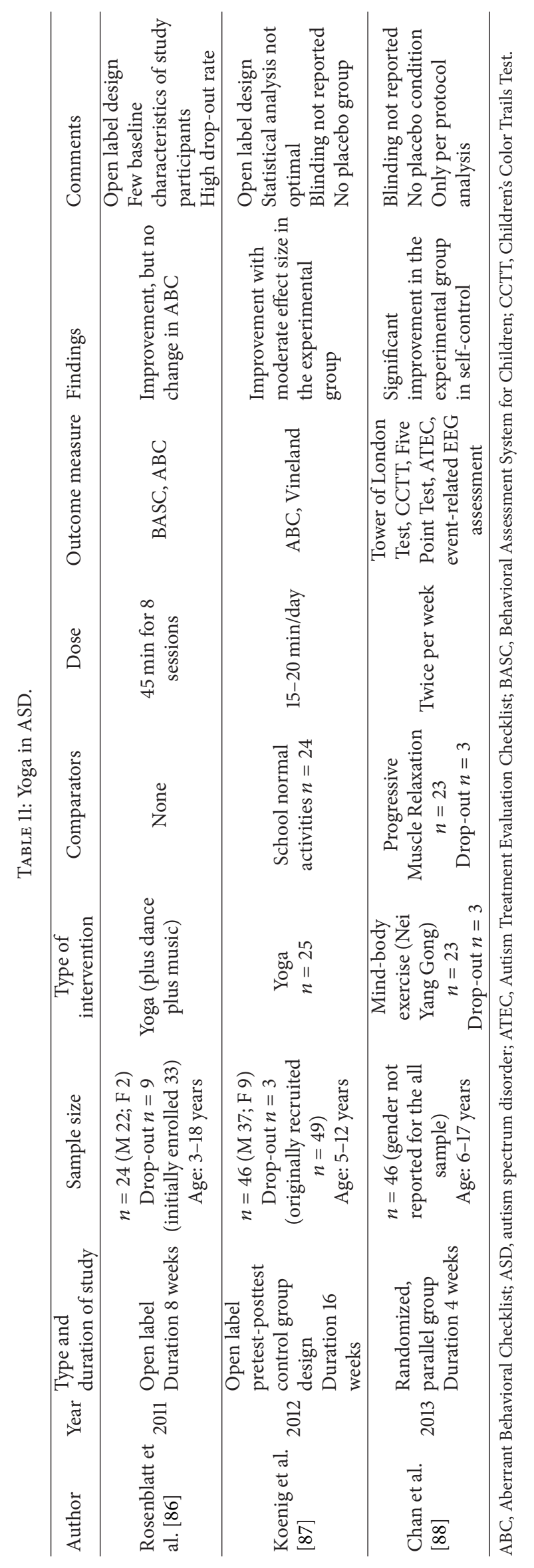




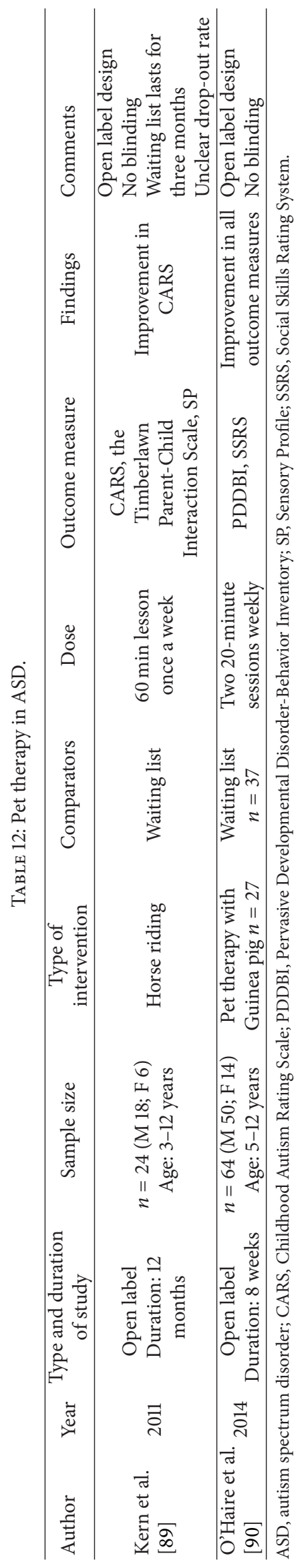




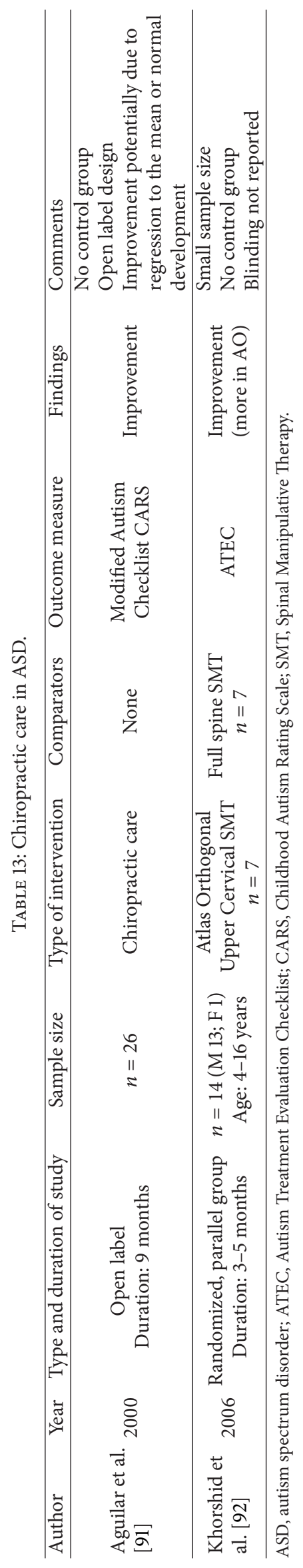


Group. However, there is an evident flaw in the study, that is, the lack of a control group.

\section{Discussion}

In recent years, CAM therapies have gained attention by the scientific community: several studies have been conducted in order to investigate the efficacy and safety of CAMs in ASD. We reviewed trials on different CAMs, but the findings are still inconclusive. In particular, there is a lack of proof regarding the efficacy of CAM in autism. It is of interest that it is striking the contrast between the wide use of CAM by families and the paucity of scientific results for alternative treatments. One possible reason for this discrepancy is that CAM therapies are usually considered as "natural," with an optimal safety profile and less side effects than conventional medications [8]. This is partly true, as nonbiological CAMs are virtually free from adverse events; unfortunately, however, several alternative treatments are prone to safety issues, such as chelation or high doses of vitamins. Additionally, even if no serious adverse events were recorded in the revised trials, some treatments as elimination diets could be associated with potentially harmful, long-term side effects, such as nutritional deficits in children with higher food selectivity. In fact, CAM appears to be safe in the short period, but no data are available for longer treatment.

Considering the reviewed treatments, among biologically based CAMs only gluten/casein-free diet, omega 3, vitamin supplementation (vitB6, vitB12, and tetrahydrobiopterin), and Hyperbaric Oxygen Therapy have been more extensively studied: all the other biological therapies were tested in single trials and therefore provided no sufficient data in order to determine their usefulness in clinical practice. Elimination diet does not appear effective in treating ASD core symptoms: the fact that individual patients may benefit from special dietary interventions could be hypothesized as the result of subclinical intolerance to specific food allergen [111]. Omega 3 supplementation provided no evidence for recommendation in ASD: the only positive results come from a single open label trial [26]. Trials evaluating vitamin supplementation yielded inconsistent results: as all studies presented several caveats, more data should be obtained before definitive judgment. Additionally, for instance, vitB12 should be administered through injection, thus potentially reducing compliance [32]. Hyperbaric Oxygen Therapy has been only recently scientifically tested: study findings are promising but not completely consistent. Future studies with larger sample size, well-designed randomization, blindness, and definition of a placebo condition will be needed.

Among nonbiologically based CAMs, the treatments more extensively investigated are music therapy, Auditory Integration Training, Sensory Integration Therapy, acupuncture, and massage. No sufficient data are available for several interventions such as dance therapy, drama therapy, or pet therapy. It is of note that music therapy is not always regarded as a CAM treatment but considered as a part of behavioral intervention [10]: this could explain the relatively high number of studies on music compared to other CAMs.
Promising evidence supports the use of music in children with ASD, which seems to impact several symptom domains such as communication, social reciprocity, and emotion. Additionally, music therapy and all nonbiological CAM treatments appear extremely safe with no side effects. Results from Auditory Integration Training studies are conflicting: more trials should be designed to better elucidate the findings; in particular, more attention should be given to blindness of investigators and assessors and to the choice of widely used standardized outcome measures. Evidences from Sensory Integration Therapy, acupuncture, and massage cautiously support the use of these treatments in clinical care: however, there are several flaws that should prevent overinterpretation of the findings (small sample sizes, unclear blinding of the assessors, lack of a defined placebo condition, and multicomponent intervention).

Overall, there is sparse evidence on the usefulness of CAM treatments in ASD. A potential explanation for these unclear results is that well-designed studies have only recently been developed and usually have limited sample size. Moreover, the heterogeneous nature of ASD and the presence of possible comorbidities could have impaired several trials which lacked a correct stratification of participants. Interestingly, almost all the reviewed trials were focused on children with ASD: as prevalence rates of ASD are increasing constantly, more adults each year are confronting the challenges of autism. Thus it will be interesting to test CAM therapies in an adult population.

We advise practitioners to encourage patients and their families to discuss the efficacy and safety of all CAMs. Patients must be informed of possible interactions between CAMs and currently prescribed drugs. Clinicians should allow families or patients to try CAMs with limited clinical evidence if they are safe and cheap and if they do not prevent patients from obtaining evidence-based treatments (i.e., behavioral therapies). It is of note that several CAMs could be easily used together with standard clinical care: in particular, nonbiologically based CAMs (i.e., music therapy, pet therapy) could be added to conventional treatment, not as a replacement but as an augmentation or implementation of standard therapy. For instance, massage or music could reduce anxiety and enhance positive response to behavioral and educational treatments. Practitioners should advise patients to try one CAM at a time and should constantly monitor clinical changes and adverse events.

In conclusion, there are still few data on the potential efficacy of CAM in autism, and no evidence-based recommendation could be done so far for the use of such therapies. To shed more light on CAM efficacy in autism, large randomized controlled trials with a better characterization of patients are needed.

\section{Conflict of Interests}

The authors declare that there is no conflict of interests regarding the publication of this paper. 


\section{References}

[1] S. Blenner and M. Augustyn, "Is the prevalence of autism increasing in the United States?" The British Medical Journal, vol. 348, Article ID g3088, 2014.

[2] S. Baron-Cohen, F. J. Scott, C. Allison et al., "Prevalence of autism-spectrum conditions: UK school-based population study," British Journal of Psychiatry, vol. 194, no. 6, pp. 500-509, 2009.

[3] T. J. Watts, “The pathogenesis of autism," Clinical Medicine Insights: Pathology, vol. 1, pp. 99-103, 2008.

[4] B. J. Tonge, K. Bull, A. Brereton, and R. Wilson, "A review of evidence-based early intervention for behavioural problems in children with autism spectrum disorder: the core components of effective programs, child-focused interventions and comprehensive treatment models," Current Opinion in Psychiatry, vol. 27, no. 2, pp. 158-165, 2014.

[5] M.-R. Mohammadi, N. Yadegari, E. Hassanzadeh et al., "Double-blind, placebo-controlled trial of risperidone plus amantadine in children with autism: a 10-week randomized study," Clinical Neuropharmacology, vol. 36, no. 6, pp. 179-184, 2013.

[6] M. Ishitobi, H. Kosaka, T. Takahashi et al., "Effectiveness and tolerability of switching to aripiprazole from risperidone in subjects with autism spectrum disorders: a prospective openlabel study," Clinical Neuropharmacology, vol. 36, no. 5, pp. 151156, 2013.

[7] V. Boon-yasidhi, P. Jearnarongrit, P. Tulayapichitchock, and J. Tarugsa, "Adverse effects of risperidone in children with autism spectrum disorders in a naturalistic clinical setting at Siriraj Hospital, Thailand," Psychiatry Journal, vol. 2014, Article ID 136158, 4 pages, 2014.

[8] J. M. Perrin, D. L. Coury, S. L. Hyman, L. Cole, A. M. Reynolds, and T. Clemons, "Complementary and alternative medicine use in a large pediatric autism sample," Pediatrics, vol. 130, no. 2, pp. S77-S82, 2012.

[9] V. A. Green, K. A. Pituch, J. Itchon, A. Choi, M. O’Reilly, and J. Sigafoos, "Internet survey of treatments used by parents of children with autism," Research in Developmental Disabilities, vol. 27, no. 1, pp. 70-84, 2006.

[10] S. E. Levy, D. S. Mandell, S. Merhar, R. F. Ittenbach, and J. A. Pinto-Martin, "Use of complementary and alternative medicine among children recently diagnosed with autistic spectrum disorder," Journal of Developmental and Behavioral Pediatrics, vol. 24, no. 6, pp. 418-423, 2003.

[11] H. H. L. Wong and R. G. Smith, "Patterns of complementary and alternative medical therapy use in children diagnosed with autism spectrum disorders," Journal of Autism and Developmental Disorders, vol. 36, no. 7, pp. 901-909, 2006.

[12] E. Hanson, L. A. Kalish, E. Bunce et al., "Use of complementary and alternative medicine among children diagnosed with autism spectrum disorder," Journal of Autism and Developmental Disorders, vol. 37, no. 4, pp. 628-636, 2007.

[13] A. M. Knivsberg, K. L. Reichelt, T. Høien, and M. Nødland, “A randomised, controlled study of dietary intervention in autistic syndromes," Nutritional Neuroscience, vol. 5, no. 4, pp. 251-261, 2002.

[14] J. H. Elder, M. Shankar, J. Shuster, D. Theriaque, S. Burns, and L. Sherrill, "The gluten-free, casein-free diet in autism: results of a preliminary double blind clinical trial," Journal of Autism and Developmental Disorders, vol. 36, no. 3, pp. 413-420, 2006.
[15] P. Whiteley, D. Haracopos, A.-M. Knivsberg et al., "The ScanBrit randomised, controlled, single-blind study of a gluten- and casein-free dietary intervention for children with autism spectrum disorders," Nutritional Neuroscience, vol. 13, no. 2, pp. 87100, 2010.

[16] C. R. Johnson, B. L. Handen, M. Zimmer, K. Sacco, and K. Turner, "Effects of gluten free/casein free diet in young children with autism: a pilot study," Journal of Developmental and Physical Disabilities, vol. 23, no. 3, pp. 213-225, 2011.

[17] A. Evangeliou, I. Vlachonikolis, H. Mihailidou et al., "Application of a ketogenic diet in children with autistic behavior: pilot study," Journal of Child Neurology, vol. 18, no. 2, pp. 113-118, 2003.

[18] S. Karkelis, O. Papadaki-Papandreou, M. Lykogeorgou, T. Papandreou, L. Lianou, and G. Chrousos, "786 elemental formula diet in autistic children," Pediatric Research, vol. 68, no. S1, pp. 397-397, 2010.

[19] A. S. Chan, S. L. Sze, Y. M. Y. Han, and M.-C. Cheung, "A Chan dietary intervention enhances executive functions and anterior cingulate activity in autism spectrum disorders: a randomized controlled trial," Evidence-Based Complementary and Alternative Medicine, vol. 2012, Article ID 262136, 11 pages, 2012.

[20] L. Y. Al-Ayadhi and N. E. Elamin, "Camel milk as a potential therapy as an antioxidant in autism spectrum disorder (ASD)," Evidence-Based Complementary and Alternative Medicine, vol. 2013, Article ID 602834, 8 pages, 2013.

[21] S. Bashir and L. Y. Al-Ayadhi, "Effect of camel milk on thymus and activation-regulated chemokine in autistic children: double-blind study," Pediatric Research, vol. 75, no. 4, pp. 559563, 2014.

[22] G. P. Amminger, G. E. Berger, M. R. Schäfer, C. Klier, M. H. Friedrich, and M. Feucht, "Omega-3 fatty acids supplementation in children with autism: a double-blind randomized, placebo-controlled pilot study," Biological Psychiatry, vol. 61, no. 4, pp. 551-553, 2007.

[23] S. Bent, K. Bertoglio, P. Ashwood, A. Bostrom, and R. L. Hendren, "A pilot randomized controlled trial of omega-3 fatty acids for autism spectrum disorder," Journal of Autism and Developmental Disorders, vol. 41, no. 5, pp. 545-554, 2011.

[24] S. Bent, R. L. Hendren, T. Zandi et al., "Internet-based, randomized, controlled trial of omega-3 fatty acids for hyperactivity in autism," Journal of the American Academy of Child and Adolescent Psychiatry, vol. 53, no. 6, pp. 658-666, 2014.

[25] N. A. Meguid, H. M. Atta, A. S. Gouda, and R. O. Khalil, "Role of polyunsaturated fatty acids in the management of Egyptian children with autism," Clinical Biochemistry, vol. 41, no. 13, pp. 1044-1048, 2008.

[26] P. Politi, H. Cena, M. Comelli et al., "Behavioral effects of omega-3 fatty acid supplementation in young adults with severe autism: an open label study," Archives of Medical Research, vol. 39, no. 7, pp. 682-685, 2008.

[27] R. G. Voigt, M. W. Mellon, S. K. Katusic et al., "Dietary docosahexaenoic acid supplementation in children with autism," Journal of Pediatric Gastroenterology and Nutrition, vol. 58, no. 6, pp. 715-722, 2014.

[28] R. L. Findling, K. Maxwell, L. Scotese-Wojtila, J. Huang, T. Yamashita, and M. Wiznitzer, "High-dose pyridoxine and magnesium administration in children with autistic disorder: an absence of salutary effects in a double-blind, placebo-controlled study," Journal of Autism and Developmental Disorders, vol. 27, no. 4, pp. 467-478, 1997. 
[29] S. Kuriyama, M. Kamiyama, M. Watanabe et al., "Pyridoxine treatment in a subgroup of children with pervasive developmental disorders," Developmental Medicine and Child Neurology, vol. 44, no. 4, pp. 284-286, 2002.

[30] L. C. Tolbert, T. Haigler, M. M. Waits, and T. Dennis, "Brief report: lack of response in an autistic population to a low dose clinical trial of pyridoxine plus magnesium," Journal of Autism and Developmental Disorders, vol. 23, no. 1, pp. 193-199, 1993.

[31] K. Bertoglio, S. Jill James, L. Deprey, N. Brule, and R. L. Hendren, "Pilot study of the effect of methyl B12 treatment on behavioral and biomarker measures in children with autism," Journal of Alternative and Complementary Medicine, vol. 16, no. 5, pp. 555-560, 2010.

[32] R. E. Frye, S. Melnyk, G. Fuchs et al., "Effectiveness of methylcobalamin and folinic acid treatment on adaptive behavior in children with autistic disorder is related to glutathione redox status," Autism Research and Treatment, vol. 2013, Article ID 609705, 9 pages, 2013.

[33] M. C. Dolske, J. Spollen, S. McKay, E. Lancashire, and L. Tolbert, "A preliminary trial of ascorbic acid as supplemental therapy for autism," Progress in Neuropsychopharmacology and Biological Psychiatry, vol. 17, no. 5, pp. 765-774, 1993.

[34] J. B. Adams, L. J. Johansen, L. D. Powell, D. Quig, and R. A. Rubin, "Gastrointestinal flora and gastrointestinal status in children with autism-comparisons to typical children and correlation with autism severity," BMC Gastroenterology, vol. 11, article 22, 2011.

[35] T. Danfors, A.-L. Von Knorring, P. Hartvig et al., "Tetrahydrobiopterin in the treatment of children with autistic disorder: a double-blind placebo-controlled crossover study," Journal of Clinical Psychopharmacology, vol. 25, no. 5, pp. 485-489, 2005.

[36] R. E. Frye, R. DeLatorre, H. B. Taylor et al., "Metabolic effects of sapropterin treatment in autism spectrum disorder: a preliminary study," Translational Psychiatry, vol. 3, article e237, 2013.

[37] C. Klaiman, L. Huffman, L. Masaki, and G. R. Elliott, “Tetrahydrobiopterin as a treatment for autism spectrum disorders: a double-blind, placebo-controlled trial," Journal of Child and Adolescent Psychopharmacology, vol. 23, no. 5, pp. 320-328, 2013.

[38] M. G. Chez, C. P. Buchanan, M. C. Aimonovitch et al., "Doubleblind, placebo-controlled study of L-carnosine supplementation in children with autistic spectrum disorders," Journal of Child Neurology, vol. 17, no. 11, pp. 833-837, 2002.

[39] A. Taliou, E. Zintzaras, L. Lykouras, and K. Francis, "An open-label pilot study of a formulation containing the antiinflammatory flavonoid luteolin and its effects on behavior in children with autism spectrum disorders," Clinical Therapeutics, vol. 35, no. 5, pp. 592-602, 2013.

[40] J. Kałuzna-Czaplińska and S. Błaszczyk, "The level of arabinitol in autistic children after probiotic therapy," Nutrition, vol. 28, no. 2, pp. 124-126, 2012.

[41] S. A. Munasinghe, C. Oliff, J. Finn, and J. A. Wray, "Digestive enzyme supplementation for autism spectrum disorders: a double-blind randomized controlled trial," Journal of Autism and Developmental Disorders, vol. 40, no. 9, pp. 1131-1138, 2010.

[42] E. Hasanzadeh, M.-R. Mohammadi, A. Ghanizadeh et al., "A double-blind placebo controlled trial of ginkgo biloba added to risperidone in patients with autistic disorders," Child Psychiatry \& Human Development, vol. 43, no. 5, pp. 674-682, 2012.

[43] T. Miyaoka, R. Wake, M. Furuya et al., "Yokukansan (TJ-54) for treatment of pervasive developmental disorder not otherwise specified and Asperger's disorder: a 12-week prospective, openlabel study," BMC Psychiatry, vol. 12, article 215, 2012.

[44] A. S. Chan, S. L. Sze, and Y. M. Y. Han, "An intranasal herbal medicine improves executive functions and activates the underlying neural network in children with autism," Research in Autism Spectrum Disorders, vol. 8, no. 6, pp. 681-691, 2014.

[45] D. Granpeesheh, J. Tarbox, D. R. Dixon, A. E. Wilke, M. S. Allen, and J. J. Bradstreet, "Randomized trial of hyperbaric oxygen therapy for children with autism," Research in Autism Spectrum Disorders, vol. 4, no. 2, pp. 268-275, 2010.

[46] D. A. Rossignol, L. W. Rossignol, S. J. Jill, S. Melnyk, and E. Mumper, "The effects of hyperbaric oxygen therapy on oxidative stress, inflammation, and symptoms in children with autism: an open-label pilot study," BMC Pediatrics, vol. 7, article 36, 2007.

[47] D. A. Rossignol, L. W. Rossignol, S. Smith et al., "Hyperbaric treatment for children with autism: a multicenter, randomized, double-blind, controlled trial," BMC Pediatrics, vol. 9, article 21, 2009.

[48] M. Sampanthavivat, W. Singkhwa, T. Chaiyakul, S. Karoonyawanich, and H. Ajpru, "Hyperbaric oxygen in the treatment of childhood autism: a randomised controlled trial," Diving and Hyperbaric Medicine, vol. 42, no. 3, pp. 128-133, 2012.

[49] J. B. Adams, M. Baral, E. Geis et al., "Safety and efficacy of oral DMSA therapy for children with autism spectrum disorders: part A-medical results," BMC Clinical Pharmacology, vol. 9, no. 1, article 16, 2009.

[50] D. A. Geier and M. R. Geier, "A clinical trial of combined antiandrogen and anti-heavy metal therapy in autistic disorders," Neuroendocrinology Letters, vol. 27, no. 6, pp. 833-838, 2006.

[51] C. H. Arezina, The Effect of Interactive Music Therapy on Joint Attention Skills in Preschool Children with Autism Spectrum Disorder, University of Kansas, 2011.

[52] M. D. Brownell, "Musically adapted social stories to modify behaviors in students with autism: four case studies," Journal of Music Therapy, vol. 39, no. 2, pp. 117-144, 2002.

[53] E. M. Buday, "The effects of signed and spoken words taught with music on sign and speech imitation by children with autism," Journal of Music Therapy, vol. 32, no. 3, pp. 189-202, 1995.

[54] K. J. Farmer, The effect of music vs. nonmusic paired with gestures on spontaneous verbal and nonverbal communication skills of children with autism ages 1-5 [M.S. thesis], Florida State University, Tallahassee, Fla, USA, 2003.

[55] G. S. Gattino, R. dos Santos Riesgo, D. Longob, J. C. L. Leite, and L. S. Faccini, "Effects of relational music therapy on communication of children with autism: a randomized controlled study," Nordic Journal of Music Therapy, vol. 20, no. 2, pp. 142-154, 2011.

[56] J. Kim, T. Wigram, and C. Gold, "The effects of improvisational music therapy on joint attention behaviors in autistic children: a randomized controlled study," Journal of Autism and Developmental Disorders, vol. 38, no. 9, pp. 1758-1766, 2008.

[57] H. A. Lim, "Effect of 'developmental speech and language training through music' on speech production in children with autism spectrum disorders," Journal of Music Therapy, vol. 47, no. 1, pp. 2-26, 2010.

[58] H. A. Lim and E. Draper, "The effects of music therapy incorporated with applied behavior analysis verbal behavior approach for children with autism spectrum disorders," Journal of Music Therapy, vol. 48, no. 4, pp. 532-550, 2011. 
[59] A. Thomas and B. C. Hunter, "The effect of music therapy on communication skills of children ages 2-3 with autism: a pilot study," in Proceedings of the American Music Therapy Association Conference, Minneapolis, Minn, USA, 2003.

[60] G. Thompson, "Family-centered music therapy in the home environment: promoting interpersonal engagement between children with autism spectrum disorder and their parents," Music Therapy Perspectives, vol. 30, no. 2, pp. 109-116, 2012.

[61] M. Boso, E. Emanuele, V. Minazzi, M. Abbamonte, and P. Politi, "Effect of long-term interactive music therapy on behavior profile and musical skills in young adults with severe autism," Journal of Alternative and Complementary Medicine, vol. 13, no. 7, pp. 709-712, 2007.

[62] E. Iseri, "Music therapy and hormonal responses in autism," Gazi Medical Journal, vol. 25, no. 2, 2014.

[63] A. Kalas, "Joint attention responses of children with autism spectrum disorder to simple versus complex music," Journal of Music Therapy, vol. 49, no. 4, pp. 430-452, 2012.

[64] L.-O. Lundqvist, G. Andersson, and J. Viding, "Effects of vibroacoustic music on challenging behaviors in individuals with autism and developmental disabilities," Research in Autism Spectrum Disorders, vol. 3, no. 2, pp. 390-400, 2009.

[65] E. T. Schwartzberg and M. J. Silverman, "Effects of music-based social stories on comprehension and generalization of social skills in children with autism spectrum disorders: a randomized effectiveness study," The Arts in Psychotherapy, vol. 40, no. 3, pp. 331-337, 2013.

[66] S. Bettison, "The long-term effects of auditory training on children with autism," Journal of Autism and Developmental Disorders, vol. 26, no. 3, pp. 361-374, 1996.

[67] S. M. Edelson, D. Arin, M. Bauman et al., "Auditory integration training: a double-blind study of behavioral and electrophysiological effects in people with autism," Focus on Autism and Other Developmental Disabilities, vol. 14, no. 2, pp. 73-81, 1999.

[68] O. C. Mudford, B. A. Cross, S. Breen et al., "Auditory integration training for children with autism: no behavioral benefits detected," American Journal on Mental Retardation, vol. 105, no. 2, pp. 118-129, 2000.

[69] B. Rimland and S. M. Edelson, "Brief report: a pilot study of auditory integration training in autism," Journal of Autism and Developmental Disorders, vol. 25, no. 1, pp. 61-70, 1995.

[70] T. Veale, "Effectiveness of AIT using the BCG device (Clark method): a controlled study," in Proceedings of the World of Options International Autism Conference, Toronto, Canada, 1993.

[71] W. Zollweg, D. Palm, and V. Vance, "The efficacy of auditory integration training: a double blind study," The American Journal of Audiology, vol. 6, no. 3, pp. 39-47, 1997.

[72] Y. Fazlioglu and G. Baran, "A sensory integration therapy program on sensory problems for children with autism," Perceptual and Motor Skills, vol. 106, no. 2, pp. 415-422, 2008.

[73] B. A. Pfeiffer, K. Koenig, M. Kinnealey, M. Sheppard, and L. Henderson, "Effectiveness of sensory integration interventions in children with autism spectrum disorders: a pilot study," American Journal of Occupational Therapy, vol. 65, no. 1, pp. 7685, 2011.

[74] C. Reilly, D. L. Nelson, and A. C. Bundy, "Sensorimotor versus fine motor activities in eliciting vocalizations in autistic children," Occupational Therapy Journal of Research, vol. 3, no. 4, pp. 199-212, 1983.
[75] C. J. Thompson, "Multi-sensory intervention observational research," International Journal of Special Education, vol. 26, no. 1, pp. 202-214, 2011.

[76] B. A. Corbett, J. R. Gunther, D. Comins et al., "Brief report: theatre as therapy for children with autism spectrum disorder," Journal of Autism and Developmental Disorders, vol. 41, no. 4, pp. 505-511, 2011.

[77] D. Mateos-Moreno and L. Atencia-Doña, "Effect of a combined dance/movement and music therapy on young adults diagnosed with severe autism," The Arts in Psychotherapy, vol. 40, no. 5, pp. 465-472, 2013.

[78] H. Allam, N. G. Eldine, and G. Helmy, "Scalp acupuncture effect on language development in children with autism: a pilot study," The Journal of Alternative and Complementary Medicine, vol. 14, no. 2, pp. 109-114, 2008.

[79] A. S. Chan, M.-C. Cheung, S. L. Sze, and W. W. Leung, "Seven-star needle stimulation improves language and social interaction of children with autistic spectrum disorders," The American Journal of Chinese Medicine, vol. 37, no. 3, pp. 495504, 2009.

[80] V. C. N. Wong and J. G. Sun, "Randomized controlled trial of acupuncture versus sham acupuncture in autism spectrum disorder," Journal of Alternative and Complementary Medicine, vol. 16, no. 5, pp. 545-553, 2010.

[81] Y.-M. Wong, "Tongue acupuncture and autism spectrum disorder," The Journal of Alternative and Complementary Medicine, vol. 16, no. 12, pp. 1247-1248, 2010.

[82] A. Escalona, T. Field, R. Singer-Strunck, C. Cullen, and K. Hartshorn, "Brief report: improvements in the behavior of children with autism following massage therapy," Journal of Autism and Developmental Disorders, vol. 31, no. 5, pp. 513-516, 2001.

[83] L. M. T. Silva, A. Cignolini, R. Warren, S. Budden, and A. Skowron-Gooch, "Improvement in sensory impairment and social interaction in young children with autism following treatment with an original Qigong massage methodology," American Journal of Chinese Medicine, vol. 35, no. 3, pp. 393-406, 2007.

[84] L. M. T. Silva, M. Schalock, R. Ayres, C. Bunse, and S. Budden, "Qigong massage treatment for sensory and self-regulation problems in young children with autism: a randomized controlled trial," American Journal of Occupational Therapy, vol. 63, no. 4, pp. 423-432, 2009.

[85] K. Piravej, P. Tangtrongchitr, P. Chandarasiri, L. Paothong, and S. Sukprasong, "Effects of Thai traditional massage on autistic children's behavior," The Journal of Alternative and Complementary Medicine, vol. 15, no. 12, pp. 1355-1361, 2009.

[86] L. E. Rosenblatt, S. Gorantla, J. A. Torres et al., "Relaxation response-based yoga improves functioning in young children with autism: a Pilot Study," Journal of Alternative and Complementary Medicine, vol. 17, no. 11, pp. 1029-1035, 2011.

[87] K. P. Koenig, A. Buckley-Reen, and S. Garg, "Efficacy of the get ready to learn yoga program among children with autism spectrum disorders: a pretest-posttest control group design," American Journal of Occupational Therapy, vol. 66, no. 5, pp. 538-546, 2012.

[88] A. S. Chan, S. L. Sze, N. Y. Siu, E. M. Lau, and M.-C. Cheung, "A chinese mind-body exercise improves self-control of children with autism: a randomized controlled trial," PLOS ONE, vol. 8, no. 7, Article ID e68184, 2013.

[89] J. K. Kern, C. L. Fletcher, C. R. Garver et al., "Prospective trial of equine-assisted activities in autism spectrum disorder," 
Alternative Therapies in Health and Medicine, vol. 17, no. 3, pp. 14-20, 2011.

[90] M. E. O’Haire, S. J. McKenzie, S. McCune, and V. Slaughter, "Effects of classroom animal-assisted activities on social functioning in children with autism spectrum disorder," The Journal of Alternative and Complementary Medicine, vol. 20, no. 3, pp. 162-168, 2014.

[91] A. Aguilar, J. Grostic, and B. Pfleger, "Chiropractic care and behavior in autistic children," Journal of Clinical Chiropractic Pediatrics, vol. 5, no. 1, pp. 293-304, 2000.

[92] K. A. Khorshid, R. W. Sweat, D. A. Zemba, and B. N. Zemba, "Clinical efficacy of upper cervical versus full spine chiropractic care on children with autism: a randomized clinical trial," Journal of Vertebral Subluxation Research, pp. 1-7, 2006.

[93] S. Tordjman, I. Najjar, E. Bellissant et al., "Advances in the research of melatonin in autism spectrum disorders: literature review and new perspectives," International Journal of Molecular Sciences, vol. 14, no. 10, pp. 20508-20542, 2013.

[94] E. L. Cooper, "The immune system and complementary and alternative medicine," Evidence-Based Complementary and Alternative Medicine, vol. 4, supplement 1, pp. 5-8, 2007.

[95] M. F. Molina, I. Sanchez-Reus, I. Iglesias, and J. Benedi, "Quercetin, a flavonoid antioxidant, prevents and protects against ethanol-induced oxidative stress in mouse liver," Biological and Pharmaceutical Bulletin, vol. 26, no. 10, pp. 1398-1402, 2003.

[96] Y. Matsuoka, D. Nishi, N. Yonemoto, K. Hamazaki, T. Hamazaki, and K. Hashimoto, "Potential role of brain-derived neurotrophic factor in omega-3 fatty acid supplementation to prevent posttraumatic distress after accidental injury: an openlabel pilot study," Psychotherapy and Psychosomatics, vol. 80, no. 5, pp. 310-312, 2011.

[97] Y. Shen, P. He, Y.-Y. Fan et al., "Carnosine protects against permanent cerebral ischemia in histidine decarboxylase knockout mice by reducing glutamate excitotoxicity," Free Radical Biology and Medicine, vol. 48, no. 5, pp. 727-735, 2010.

[98] J. F. Risher and S. N. Amler, "Mercury exposure: evaluation and intervention. The inappropriate use of chelating agents in the diagnosis and treatment of putative mercury poisoning," NeuroToxicology, vol. 26, no. 4, pp. 691-699, 2005.

[99] M. H. Bennett, B. Trytko, and B. Jonker, "Hyperbaric oxygen therapy for the adjunctive treatment of traumatic brain injury," Cochrane Database of Systematic Reviews, no. 4, Article ID CD004609, 2004.

[100] S. E. Levy and S. L. Hyman, "Complementary and alternative medicine treatments for children with autism spectrum disorders," Child and Adolescent Psychiatric Clinics of North America, vol. 17, no. 4, pp. 803-820, 2008.

[101] N. M. Lau, P. H. R. Green, A. K. Taylor et al., "Markers of celiac disease and gluten sensitivity in children with autism," PLoS ONE, vol. 8, no. 6, Article ID e66155, 2013.

[102] L. de Magistris, A. Picardi, D. Siniscalco et al., "Antibodies against food antigens in patients with autistic spectrum disorders," BioMed Research International, vol. 2013, Article ID 729349, 11 pages, 2013.

[103] K. L. Reichelt, D. Tveiten, A.-M. Knivsberg, and G. Brønstad, "Peptides' role in autism with emphasis on exorphins," Microbial Ecology in Health and Disease, vol. 23, Article ID 18958, 2012.

[104] K. Horvath, J. C. Papadimitriou, A. Rabsztyn, C. Drachenberg, and J. Tyson Tildon, "Gastrointestinal abnormalities in children with autistic disorder," Journal of Pediatrics, vol. 135, no. 5, pp. 559-563, 1999.
[105] J. T. Nigg and K. Holton, "Restriction and elimination diets in ADHD treatment," Child and Adolescent Psychiatric Clinics of North America, vol. 23, no. 4, pp. 937-953, 2014.

[106] G. Joshi, S. V. Faraone, J. Wozniak et al., "Symptom profile of ADHD in youth with high-functioning autism spectrum disorder: a comparative study in psychiatrically referred populations," Journal of Attention Disorders, 2014.

[107] A.-M. Knivsberg, K. Wiig, G. Lind, M. Nodland, and K. L. Reichelt, "Dietary intervention in autistic syndromes," Brain Dysfunction, vol. 3, pp. 315-327, 1990.

[108] W. H. Reichelt, A.-M. Knivsberg, M. Nødland, M. Stensrud, and K. L. Reichelt, "Urinary peptide levels and patterns in autistic children from seven countries, and the effect of dietary intervention after 4 years," Developmental Brain Dysfunction, vol. 10, no. 1, pp. 44-55, 1997.

[109] P. Whiteley, J. Rodgers, D. Savery, and P. Shattock, "A glutenfree diet as an intervention for autism and associated spectrum disorders: preliminary findings," Autism, vol. 3, no. 1, pp. 45-65, 1999.

[110] R. G. Levy, P. N. Cooper, and P. Giri, "Ketogenic diet and other dietary treatments for epilepsy," Cochrane Database of Systematic Reviews, vol. 3, Article ID CD001903, 2012.

[111] H. Jyonouchi, "Autism spectrum disorders and allergy: observation from a pediatric allergy/immunology clinic," Expert Review of Clinical Immunology, vol. 6, no. 3, pp. 397-411, 2010.

[112] K. W. Fan, "National center for complementary and alternative medicine website," Journal of the Medical Library Association, vol. 93, no. 3, p. 3, 2005.

[113] E. M. Alissa and G. A. Ferns, "Functional foods and nutraceuticals in the primary prevention of cardiovascular diseases," Journal of Nutrition and Metabolism, vol. 2012, Article ID 569486, 16 pages, 2012.

[114] S. Yehuda, S. Rabinovitz, and D. I. Mostofsky, "Essential fatty acids and the brain: from infancy to aging," Neurobiology of Aging, vol. 26, supplement 1, pp. S98-S102, 2005.

[115] S. James, P. Montgomery, and K. Williams, "Omega-3 fatty acids supplementation for autism spectrum disorders (ASD)," Cochrane Database of Systematic Reviews, vol. 11, Article ID CD007992, 2011.

[116] R. L. Lindsay, L. E. Arnold, M. G. Aman et al., "Dietary status and impact of risperidone on nutritional balance in children with autism: a pilot study," Journal of Intellectual and Developmental Disability, vol. 31, no. 4, pp. 204-209, 2006.

[117] D. W. Lockner, T. K. Crowe, and B. J. Skipper, "Dietary intake and parents' perception of mealtime behaviors in preschool-age children with autism spectrum disorder and in typically developing children," Journal of the American Dietetic Association, vol. 108, no. 8, pp. 1360-1363, 2008.

[118] C. Sun, W. Xia, Y. Zhao, N. Li, D. Zhao, and L. Wu, "Nutritional status survey of children with autism and typically developing children aged 4-6 years in Heilongjiang Province, China," Journal of Nutritional Science, vol. 2, article e16, 2013.

[119] Y. Tani, E. Fernell, Y. Watanabe, T. Kanai, and B. Langstrom, "Decrease in 6R-5,6,7,8-tetrahydrobiopterin content in cerebrospinal fluid of autistic patients," Neuroscience Letters, vol. 181, no. 1-2, pp. 169-172, 1994.

[120] C. Nye and A. Brice, "Combined vitamin B6-magnesium treatment in autism spectrum disorder," Cochrane Database of Systematic Reviews, no. 4, Article ID CD003497, 2005.

[121] J. B. Adams, T. Audhya, S. McDonough-Means et al., "Effect of a vitamin/mineral supplement on children and adults with autism," BMC Pediatrics, vol. 11, no. 1, article 111, 2011. 
[122] S. Coghlan, J. Horder, B. Inkster, M. A. Mendez, D. G. Murphy, and D. J. Nutt, "GABA system dysfunction in autism and related disorders: from synapse to symptoms," Neuroscience and Biobehavioral Reviews, vol. 36, no. 9, pp. 2044-2055, 2012.

[123] P. Q. Trombley, M. S. Horning, and L. J. Blakemore, "Interactions between carnosine and zinc and copper: implications for neuromodulation and neuroprotection," Biochemistry, vol. 65, no. 7, pp. 807-816, 2000.

[124] S. Rose, S. Melnyk, O. Pavliv et al., "Evidence of oxidative damage and inflammation associated with low glutathione redox status in the autism brain," Translational Psychiatry, vol. 2, p. e134, 2012.

[125] K. Kaviarasan and K. V. Pugalendi, "Influence of flavonoidrich fraction from Spermacoce hispida seed on PPAR-alpha gene expression, antioxidant redox status, protein metabolism and marker enzymes in high-fat-diet fed STZ diabetic rats," Journal of Basic and Clinical Physiology and Pharmacology, vol. 20, no. 2, pp. 141-158, 2009.

[126] E. A. Mayer, D. Padua, and K. Tillisch, "Altered brain-gut axis in autism: comorbidity or causative mechanisms?” BioEssays, vol. 36, no. 10, pp. 933-939, 2014.

[127] N. Brondino, A. De Silvestri, S. Re et al., "A systematic review and meta-analysis of ginkgo biloba in neuropsychiatric disorders: from ancient tradition to modern-day medicine," Evidence-Based Complementary and Alternative Medicine, vol. 2013, Article ID 915691, 11 pages, 2013.

[128] A. L. Gill and C. N. A. Bell, "Hyperbaric oxygen: its uses, mechanisms of action and outcomes," QJM, vol. 97, no. 7, pp. 385-395, 2004.

[129] T. N. Davis, M. O’Reilly, S. Kang et al., "Chelation treatment for autism spectrum disorders: a systematic review," Research in Autism Spectrum Disorders, vol. 7, no. 1, pp. 49-55, 2013.

[130] K. E. Bruscia, "Music in the assessment and treatment of echolalia," Music Therapy, vol. 2, no. 1, pp. 25-41, 1982.

[131] M. S. Solanki, M. Zafar, and R. Rastogi, "Music as a therapy: role in psychiatry," Asian Journal of Psychiatry, vol. 6, no. 3, pp. 193-199, 2013.

[132] J. Alvin and A. Warwick, Music Therapy for the Autistic Child, Oxford University Press, Oxford, UK, 2nd edition, 1991.

[133] A. Brandt, M. Gebrian, and L. R. Slevc, "Music and early language acquisition," Frontiers in Psychology, vol. 3, article 327, 2012.

[134] M. Sharda, R. Midha, S. Malik, S. Mukerji, and N. C. Singh, "Fronto-temporal connectivity is preserved during sung but not spoken word listening, across the autism spectrum," Autism Research, 2014.

[135] M. Geretsegger, C. Elefant, K. A. Mössler, and C. Gold, "Music therapy for people with autism spectrum disorder," Cochrane Database of Systematic Reviews, vol. 6, Article ID CD004381, 2014.

[136] Y. Sinha, N. Silove, A. Hayen, and K. Williams, "Auditory integration training and other sound therapies for autism spectrum disorders (ASD)," Cochrane Database of Systematic Reviews, no. 12, Article ID CD003681, 2011.

[137] S. Wigham, J. Rodgers, M. South, H. McConachie, and M. Freeston, "The interplay between sensory processing abnormalities, intolerance of uncertainty, anxiety and restricted and repetitive behaviours in autism spectrum disorder," Journal of Autism and Developmental Disorders, vol. 45, no. 4, pp. 943-952, 2015.

[138] J. Case-Smith and T. Bryan, "The effects of occupational therapy with sensory integration emphasis on preschool-age children with autism," American Journal of Occupational Therapy, vol. 53, no. 5, pp. 489-497, 1999.

[139] L. R. Chasen, Social Skills, Emotional Growth, and Drama Therapy: Inspiring Connection on the Autism Spectrum, Jessica Kingsley Publishers, London, UK, 2011.

[140] L. M. McGarry and F. A. Russo, "Mirroring in dance/movement therapy: potential mechanisms behind empathy enhancement," The Arts in Psychotherapy, vol. 38, no. 3, pp. 178-184, 2011.

[141] American Psychiatric Association, Diagnostic and Statistical Manual of Mental Disorders, American Psychiatric Association, Washington, DC, USA, 5th edition, 2013.

[142] T. Grandin, "Calming effects of deep touch pressure in patients with autistic disorder, college students, and animals," Journal of Child and Adolescent Psychopharmacology, vol. 2, no. 1, pp. 6372, 1992.

[143] M. S. Lee, J. I. Kim, and E. Ernst, "Massage therapy for children with autism spectrum disorders: a systematic review," Journal of Clinical Psychiatry, vol. 72, no. 3, pp. 406-411, 2011.

[144] C. C. Streeter, J. E. Jensen, R. M. Perlmutter et al., "Yoga Asana sessions increase brain GABA levels: a pilot study," Journal of Alternative and Complementary Medicine, vol. 13, no. 4, pp. 419426, 2007.

[145] A. Funahashi, A. Gruebler, T. Aoki, H. Kadone, and K. Suzuki, "Brief report: the smiles of a child with autism spectrum disorder during an animal-assisted activity may facilitate social positive behaviors-quantitative analysis with smile-detecting interface," Journal of Autism and Developmental Disorders, vol. 44, no. 3, pp. 685-693, 2014.

[146] P. M. Barnes, B. Bloom, and R. L. Nahin, "Complementary and alternative medicine use among adults and children: United States, 2007," National Health Statistics Reports, no. 12, pp. 1-23, 2009.

[147] J. Alcantara, J. D. Alcantara, and J. Alcantara, "A systematic review of the literature on the chiropractic care of patients with autism spectrum disorder," Explore: The Journal of Science and Healing, vol. 7, no. 6, pp. 384-390, 2011. 


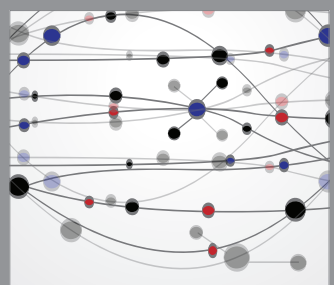

The Scientific World Journal
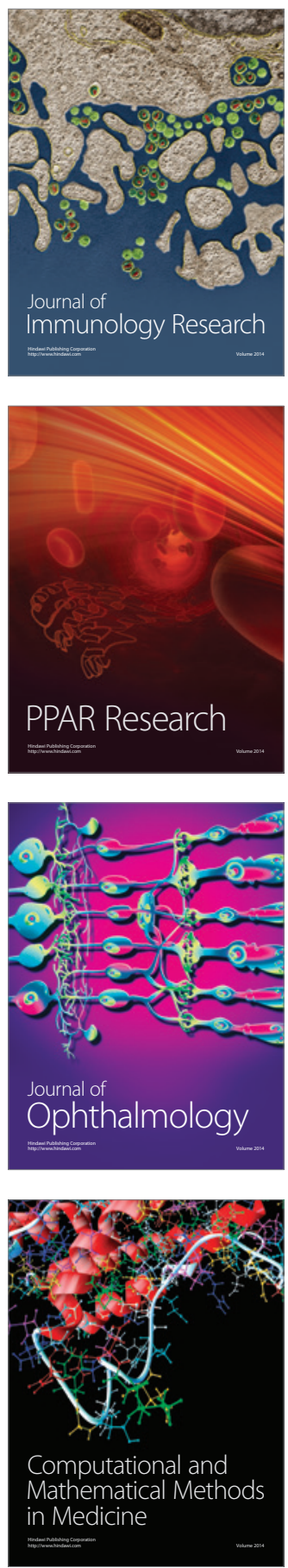

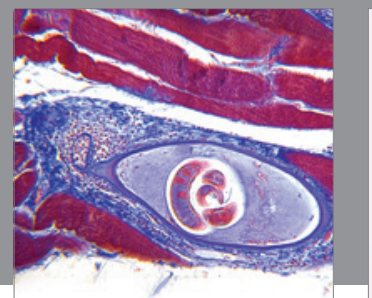

Gastroenterology

Research and Practice
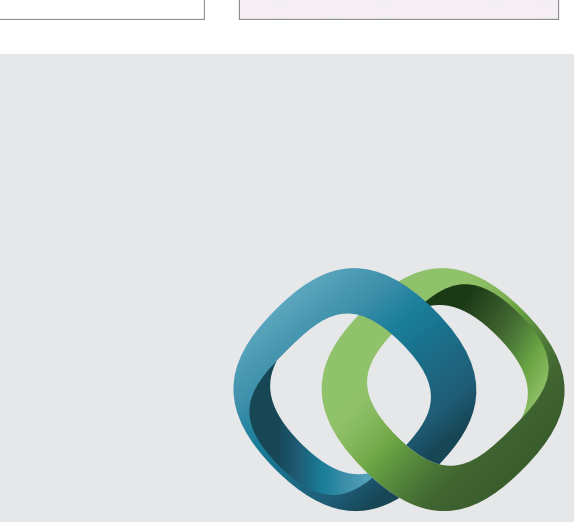

\section{Hindawi}

Submit your manuscripts at

http://www.hindawi.com
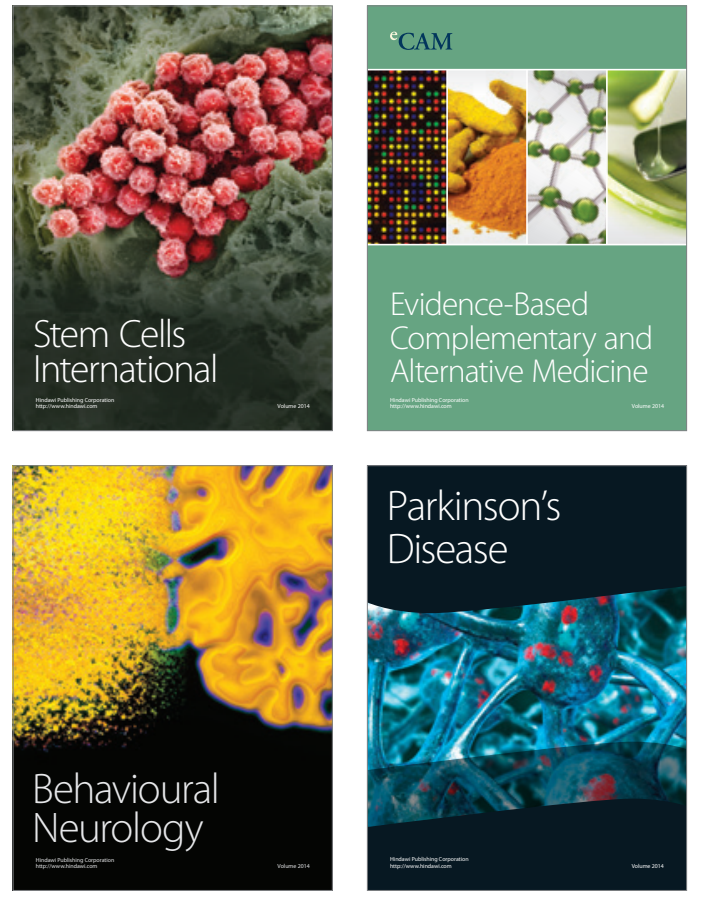
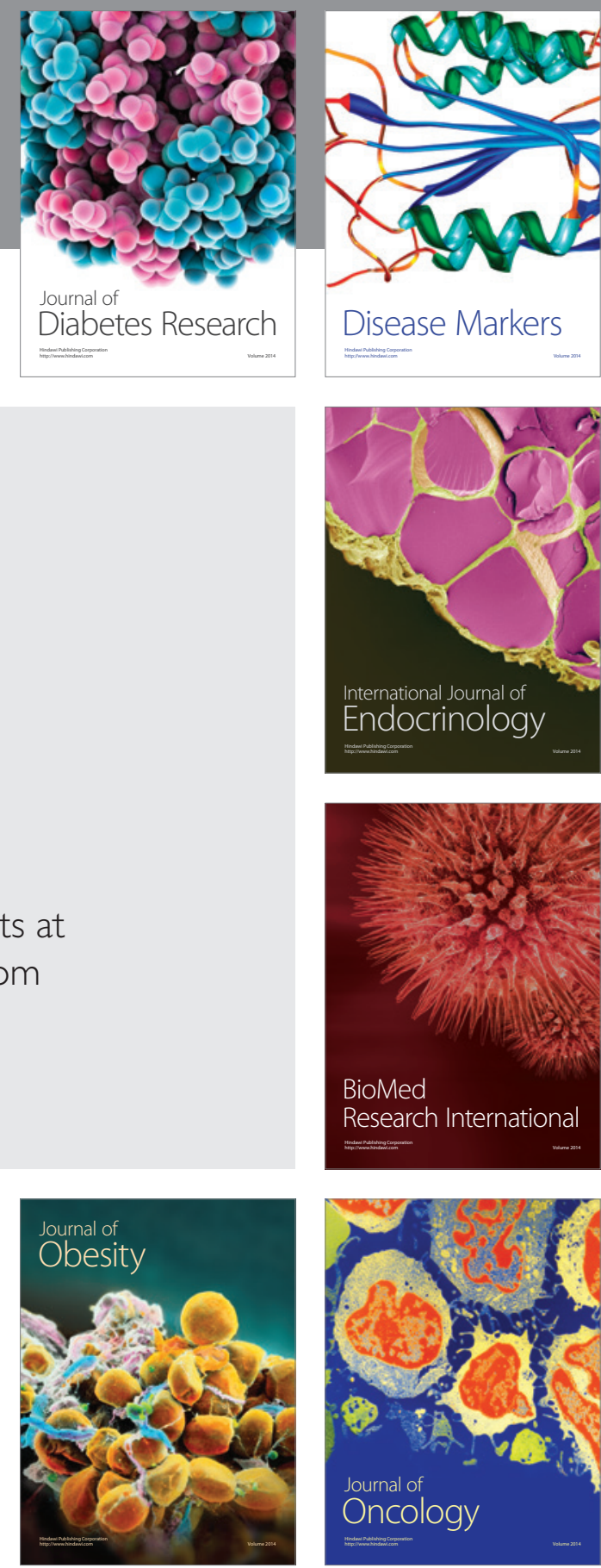

Disease Markers
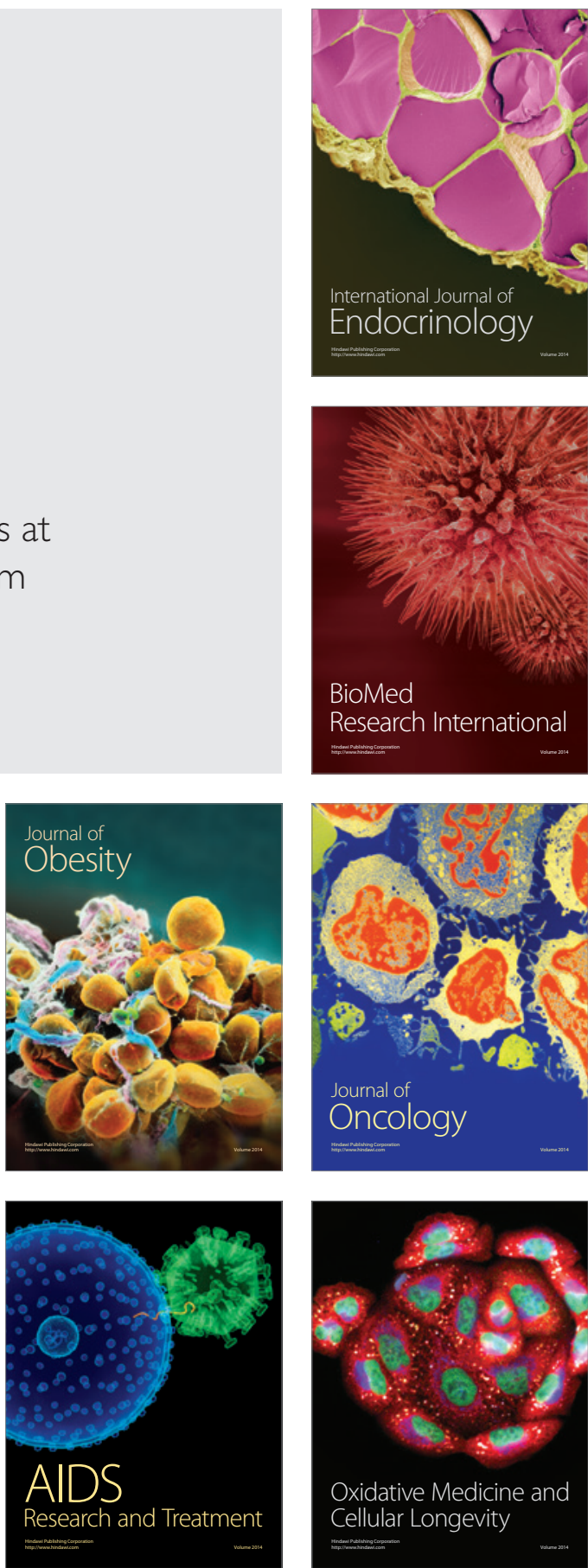